\title{
The Economics of Investor Protection: ISDS versus National Treatment
}

\author{
Wilhelm Kohler \\ Frank Stähler
}

CESIFO WORKING PAPER NO. 5766

CATEgory 8: Trade Policy

ORIGINAL VERSION: FEBRUARY 2016

THIS VERSION: August 2019

An electronic version of the paper may be downloaded

- from the SSRN website:

- from the RePEc website:

- from the CESifo website: WWw.SSRN.com

www.RePEc.org

www.CESifo-group.org/wp 


\title{
The Economics of Investor Protection: ISDS versus National Treatment
}

\begin{abstract}
Investor-state dispute settlements (ISDS) are supposed to protect foreign investors against domestic policies causing "unjustified" harm. This paper scrutinizes the effects of ISDS and national treatment provisions in a two-period model where foreign investment is subject to a hold-up problem. It shows that ISDS may increase welfare, but comes with additional regulatory distortions in the first period. A national treatment provision avoids these regulatory distortions, but implies entry distortions because it makes the hold-up problem also apply to domestic firms. If the domestic regulatory framework applies to many domestic firms, a national treatment provision welfare-dominates ISDS.
\end{abstract}

JEL-Codes: F210, F230, F530, F550.

Keywords: investor-state dispute settlement, national treatment provision, foreign direct investment, TTIP, TPP, regulation.

Wilhelm Kohler

University of Tübingen

Institute for Applied Economic Research

Mohlstr. 36 (V2)

Germany - 72074 Tübingen

wilhelm.kohler@uni-tuebingen.de
Frank Stähler

University of Tübingen

Mohlstr. 36 (V4)

Germany-72074 Tübingen

frank.staehler@uni-tuebingen.de

Version of August 20, 2019

This paper has been presented at the CESifo Area Conference on Global Economy and at several seminars. We wish to thank the participants, Davin Chor, Martin Richardson, Thomas Zylkin, two referees and an associate editor for very helpful comments. Wilhelm Kohler gratefully acknowledges financial support received from the Deutsche Forschungsgemeinschaft (DFG) under Grant No. KO 1393/2-1. Frank Stähler gratefully acknowledges financial support received from the Australian Research Council under project number DP190103524. 


\section{Introduction}

International investment agreements often include investor protection provisions such as investor-state dispute settlement (ISDS) mechanisms. These provisions are supposed to protect a foreign investor against a government that cares about the well-being of all national actors, but does not take foreign investor profit into account. The issue has gained a high level of public attention, in particular through controversy over whether these provisions should be part of future multilateral trade and investment agreements. ISDS provisions are rather universal; already in 2012 ISDS provisions were present in as many as $93 \%$, or some 3.000 international investment agreements (see OECD, 2012). Existing and proposed ISDS mechanisms follow procedures separate from the host country's legal system, mostly relying on ad hoc panels that decide on monetary compensations of foreign investors for increases in costs, or reductions in revenues, that are caused by "unjustified" government regulation 1 According to UNCTAD, known treaty-based arbitrations amount to 942 cases of which 602 have been concluded. Of the concluded cases, $35.7 \%$ were won by states, $28.7 \%$ were won by investors, and the remainder was either settled, discontinued or decided in favor of neither party. Of 164 cases won by investors, more than USD 10 (100) million were awarded in 110 (43) cases. The number of initiated arbitrations has experienced some variation in the last years, with a low of 68 in 2013 and a high of 83 in 20152

Why should foreign investors enjoy a treatment that is denied to domestic investors? Any long-term investment, domestic and foreign, is subject to the risk of future government policies endangering ex post profitability of the investment. But there is a crucial difference: when deciding on its policies, the government will take into account the effects on domestic investor profits, whereas the same is not true for foreign investor profit.

\footnotetext{
${ }^{1}$ Monetary compensations are not known in international trade agreements as retaliation is provided instead (see Maggi and Staiger, 2015). However, the notion of monetary government-to-investor compensation is very common in international investment treaties; see again OECD (2012).

${ }^{2}$ See http://investmentpolicyhub.unctad.org/ISDS (accessed August 16, 2019). Most cases affect foreign investment in the energy sector (178), and since UNCTAD also classifies cases sectorally and offers a summary of each dispute, a lot of cases seem to be firm-specific in nature.
} 
While host country governments typically have an interest in foreign investment, due to some positive spillover, they will ignore the impact of a more stringent regulation on foreign investors' profits once the investment is made. Since governments are sovereign, ex ante enforceable contracts on regulatory behavior are infeasible. As a result, beneficial investments may not be carried out at all, or not carried out to the socially optimal extent.

We prefer so see this as an instance of the so-called hold-up problem. A hold-up problem arises whenever a relationship between two parties is characterized by the following conditions: (i) At least one of the two parties may undertake a costly investment that benefits the outcome of the relationship. (ii) The return to that investment if used within the relationship is larger than if used outside the relationship (relationship-specificity). (iii) The two parties cannot enter an ex ante enforceable contract on the investment, say due to ex post non-verifiability by a third party (see Che and Sákovics, 2008). The literature typically discusses hold-up problems arising in private relationships ${ }^{3}$ In our case the relationship is between foreign investors and the host country government which benefits from foreign investment through some spill-over to the domestic economy. A hold-up problem arises because - once investors have entered - their investment is virtually locked in and cannot be undone or relocated to some other country. Furthermore, the government's regulatory policy, which must be seen as its contribution to the relationship, is not contractible prior to investor entry and cannot be part of a credible commitment to some policy rule. Anticipating a regulatory policy that ignores their interest, foreign investors will enter to a sub-optimally low extent. This is analogous to anticipating the outcome of ex post Nash bargaining between private parties, which similarly dilutes the investor

\footnotetext{
${ }^{3}$ An early instance is Grout (1984) who discusses the relationship between (unionized) workers and the owner(s) of a firm. Grossman and Hart (1986) have sparked off a whole literature dealing with relationships between a selling and a buying firm, suggesting a partial remedy of the hold-up problem through a suitable allocation of residual ownership rights. Antràs (2003) has introduced this idea to the literature on global sourcing of intermediate inputs, which is conveniently surveyed in by Antràs (2016). Throughout this literature, absent enforceable contracts, private parties engage in ex post bargaining about the surplus of the relationship materializing after investments have been made. The ex-post bargaining power of the two parties determines the shares of the surplus going to the two parties, which in turn determine their ex-ante investment incentives. Anticipating the bargaining outcome, investing parties fail to internalize the full marginal benefit of their investment, whence the relationship will be plagued by inefficient levels of investment.
} 
interest in the hold-up relationships between private parties. Obviously, the hold-up remedies usually suggested for relationships between private parties (e.g., vertical integration, residual property rights) are infeasible with investor-state relationships. Hence the desire to achieve some efficiency increase through ex post ISDS provisions aiming at compensation. This is similar to tax holidays for foreign investors (see e.g. Bond and Samuelson, 1986), but ISDS compensations are paid ex post while tax holidays are granted ex ante in order to front-load the benefits of foreign entry.

Sub-optimal levels of foreign investment have also been discussed in models allowing for ex post expropriation by host-country governments, starting with the pioneering contribution by Eaton and Gersovitz (1984). There is a clear analogy in that eroding an investment's ex post profitability through national interest policies would seem economically equivalent to partial expropriation. Indeed, the ISDS provisions in existing agreements make explicit reference to "measures equivalent to expropriations" (see below). However, we argue that the economics of ISDS is best understood as an attempted remedy of a hold-up problem. That being said, however, it is interesting to note that in Eaton and Gersovitz (1984) a penalty imposed on expropriation may benefit the expropriating country. In our case, too, an ISDS provision potentially penalizing the host country will under certain conditions benefit the host country.

It is often argued that any anticipation of ISDS prompts the government to soften its regulatory stance ("regulatory chill"). However, a change in the government's regulatory behavior is the very objective of ISDS in the first place. The question is whether this change in behavior increases efficiency. Moreover, under plausible conditions an ISDS mechanism triggers an intertemporal trade-off. A lenient present standard may attract FDI, but it also increases the odds that the government will want to increase its regulatory stringency in the future. If increasing regulatory stringency entails ISDS-imposed compensation payments, then a lower present regulatory standard increases the expected cost of adjusting the standard in the future. Conversely, imposing a more stringent regulatory standard may reduce the present inflow of FDI, but it will give the government more discretion in the future, without facing a compensation threat. 
It is this intertemporal trade-off that we analyze in the first part of this paper. We develop a two-period model that highlights this trade-off and allows us to identify conditions under which ISDS does indeed mitigate the hold-up problem vis à vis foreign investors. Within each period, a more stringent regulation delivers welfare gains (say less pollution), but it also causes a welfare loss because FDI generates a positive spillover to the domestic economy, and more stringent regulation reduces FDI. We allow for an FDI entry subsidy as a second policy instrument which the government may use to influence the level of foreign investment in period one. As we shall see, the government will overregulate in period two, causing suboptimally low entry despite the entry subsidy. An ISDS mechanism puts period two regulation under a liability rule, which makes the government (partly) internalize foreign investors' profits and which potentially improves efficiency. However, due to the aforementioned intertemporal trade-off it also affects period one regulation. We show that ISDS distorts first-period regulation and reduces overregulation in the second period, and we characterize the conditions under which ISDS is welfare-improving.

We then compare ISDS with a national treatment provision. National treatment means that the government is not allowed to discriminate between domestic and foreign firms. This seems like a natural way of forcing the government to take into account foreign investors' profits, since any regulation will always impact domestic and foreign firms on an equal footing. However, it introduces a new distortion, having to do with entry of foreign firms. The government now deals with a mix of domestic and foreign firms, and the share of domestic firms becomes pivotal. The presence of a hold-up problem vis à vis foreign firms inflicts a damage on domestic firms who are, in effect, taken hostage to this problem through the national treatment provision. For a given number of domestic firms, this damage is the larger, the larger the number of foreign firms. Anticipating this effect, the government wants to discourage entry so as to keep the share of foreign firms small. However, if the number of domestic firms is sufficiently large, this effect will be small to begin with, and we show that a national treatment provision welfare-dominates ISDS if the number of domestic firms is not too small and an increase in this number reduces the holdup incentive. These conditions are more likely to be fulfilled if the regulatory framework 
is not firm- or industry-specific, and thus the role a national treatment provision can play for fixing the hold-up problem crucially depends on the regulatory design.

Most of the literature on ISDS is empirical and offers little guidance on the tradeoffs implied by different investor protection mechanisms. This literature regards investor protection provisions as a means of attracting FDI, in particular for developing countries where institutional investor protection might be underdeveloped 4 and thus it shares some features with the literature on tax competition! $5^{5}$ Our focus here is not on competition for FDI, but on the welfare implications of different forms of investor protection. The reason is twofold: First, we want to keep the model as simple as possible to start with, and thus we do not consider strategic interactions among countries or among firms. Second, investor protection provisions, particularly ISDS, have been hotly debated in countries negotiating trade deals like the Transatlantic Trade and Investment Partnership (TTIP) between the EU and the US, or the Trans-Pacific Partnership (TPP) between the US and 11 other pacific countries. While negotiations for both agreements have been abandoned by the US, TPP is now considered a blueprint for future agreements, both bilateral and multilateral ${ }^{6}$ In this type of agreement, investor protection can no longer be used strategically for attracting FDI as it affects all signatory countries.

Theoretical papers have a different focus. Janeba (2019) deals with the regulatory chill effect of ISDS and finds - as we do - that this effect is ambiguous. Horn and Tangerås (2017) explore the efficiency properties of compensatory schemes in an environment where regulation means effectively shutting down production from FDI. Examining strategic interactions between regulators and/or firms, Konrad (2017) shows that the existence of large investors may lead to overinvestment and excessively permissive regulation. Schjelderup and Stähler (2019) show why multinational firms have an interest

\footnotetext{
${ }^{4}$ See for example Neumayer et al. (2016). These authors suggest that the increase in ISDS provisions is due to a "contagion" effect. We do not study the potential dynamics of international investment agreements but focus on the effects of different provisions in an agreement.

${ }^{5}$ See, for example, Haufler and Wooton $(1999,2010)$.

${ }^{6}$ In fact, TTP-11, i.e., without the US, has come into force, but without ISDS and intellectual rights provisions that had been part of the TPP draft. These have been suspended, also with the vision that they might be reintroduced once a US administration would want to rejoin TPP.
} 
in ISDS provisions beyond potential compensation as it allows them to be more aggressive on markets. Closer to our paper is Aisbett et al. (2010a) who discuss the role of compensations if regulation makes a foreign investment worthless. In their framework, a court may decide in favor of compensations the higher the ex ante probability of harm caused by the investment. In our model, regulation reduces, but does not necessarily eliminate investor profit. 7 Our paper is also related to the literature on inter-governmental dispute settlement under the auspices of the WTO and its effects on firm behavior 8 The difference is that we focus on dispute settlement between private investors and the government in the specific context of regulatory standards pertaining to investment projects. We are concerned with the incentive problems deriving from asymmetric information and incomplete contracts between foreign investors and the host country government in cases where investors are locked in after entry, and we explore the efficiency properties of ISDS and national treatment mechanisms that are commonly proposed as potential solutions to these problems.

There is also a literature on the formation and the impact of international investment agreements. One strand of this literature has explored which type of countries are more likely to sign bilateral investment treaties (BITs). For example, Bergstrand and Egger (2013) consider the co-existence of BITs and PTAs (preferential trade agreements) and show that the likelihood of both a BIT and a PTA is higher between two countries with larger and more similar GDP, but that an increase in relative factor endowments decreases the likelihood of a BIT, while making a PTA more likely. The other strand of the literature has investigated whether BITs increase FDI. For example, Egger and Merlo (2012) show for German multinationals that BITs increase both the number of multinational firms and the number of plants per firm. However, measuring regulatory stringency by the presence

\footnotetext{
${ }^{7}$ Their framework bears close resemblance to the literature on land takings, as pioneered by Blume et al. (1984). Aisbett et al. (2010b) discuss optimal compensations in a model in which a regulator can only close down a foreign operation and a court deciding on compensations receives a stochastic signal, but ISDS tribunals do have little in common with independent courts. See in particular footnote 10 for the appointment procedure suggested for TPP.

${ }^{8}$ For models on the effect of firm behavior to WTO rules, see for example Anderson (1992), Bagwell and Staiger (1990) and Maggi and Staiger $(2011,2015)$ There is also a literature why trade agreements are flexible, see Beshkar and Bond (2010), Horn et al. (2010).
} 
of ISDS provisions, Berger et al. (2011) show that more stringent BITs do not necessarily lead to more FDI.

We wish to highlight right from the start that our modeling framework stacks the deck in favor of ISDS because our model cannot address a number of problems associated with ISDS. First, we ignore all procedural and legal costs associated with ISDS, which can be substantial..$^{9}$ Second, we take the ownership structure of firms as given (distinguishing only domestic and foreign firms) and do not allow for strategic ownership changes in response to ISDS, although we discuss some aspects of this issue at the end of Section 3 . Third, we do not take into account that an ISDS panel may rule on its own, may not follow best practice procedures when appointing its members, and may face little or no control by law-makers in the signatory countries 10 This setup may violate the Rule of Law in several countries, creating an economic "Guantanamo Bay", and the costs of by-passing legal procedures will not be easy to assess, but could be substantial.

The remainder of this paper is organized as follows. Section 2 sets up the basic model and develops the outcome without any ISDS provision. Section 3 extends this model to the case of ISDS and develops the regulatory regime in the presence of ISDS, and our modeling of the ISDS provision will follow closely the details of investment agreements, for example the TPP draft. Section 4 discusses a national treatment provision and compares it to an ISDS provision. Section 5 concludes.

\footnotetext{
${ }^{9}$ For example, the Transnational Institute (2017) reports that Ecuador plans to terminate all of its 16 remaining BITs also because it had to pay USD 156 million to international law firms. Furthermore, investors have won 13 cases, the state of Ecuador only one.

${ }^{10}$ Article 9.22 of the TPP draft (2016), for example, specified for the appointment of the ISDS tribunal that " $[\mathrm{u}]$ nless the disputing parties agree otherwise, the tribunal shall comprise three arbitrators, one arbitrator appointed by each of the disputing parties and the third, who shall be the presiding arbitrator, appointed by agreement of the disputing parties." In the context of TTIP, the use of ad hoc panels had been questioned on legal grounds. To allay legal concerns, the European Commission had therefore proposed to establish an international investment court featuring an appellate mechanism with tenured judges, in order to ease the legal concerns about dispute settlement through ad hoc panels; see http://trade.ec.europa.eu/doclib/docs/2015/may/tradoc_153408.PDF for an account of the EU's negotiation position on ISDS and Titi (2016).
} 


\section{A model of international investment}

We look at two countries, domestic and foreign, where foreign investors consider establishing an affiliate in the home country. We focus on the domestic country, but the model is readily extended to reciprocal FDI such that similar effects materialize in the foreign country dealing with domestic investors. Investors' profits are affected by a regulatory standard set by the domestic government. For the basic model and the subsequent section, we consider foreign investors only, as the purpose of the model is to highlight the economic problem an ISDS provision is meant to address, and in line with common practice we assume that any ISDS provision is designed for foreign investors only. We will be more explicit on the role of domestic firms versus foreign investors further below when dealing with a national treatment provision as the principal alternative to ISDS.

\subsection{Domestic regulation and lack of commitment}

There are two periods, and the sequence of decisions is as follows: at the beginning of period one, the risk-neutral government decides upon a regulatory standard as well as an entry subsidy, immediately followed by investors' entry decisions. Potential investors are also risk-neutral and their mass is normalized to unity. Entry means incurring a fixed cost and earning profits in periods one and two, depending on regulatory standards. Upon entry, investors are locked in for both periods. In period two, the government is confronted with a new environment and has the chance to set a new regulatory standard. We use $\theta_{t}>0$ to denote the period $t$ sensitivity of welfare with respect to regulation, and $\theta_{t} v\left(s_{t}\right)$ is the domestic benefit that derives from the regulatory standard $s_{t}, 0 \leq s_{t}<\infty$. Plausibly, we assume $v^{\prime}\left(s_{t}\right)>0$ and $v^{\prime \prime}\left(s_{t}\right)<0$, i.e., a decreasing marginal benefit of regulatory tightening. The host government realizes $\theta_{1}$ before setting its regulatory standard $s_{1}$ and before investors decide upon entry at the beginning of period one ${ }^{11}$ At the time of entry,

\footnotetext{
${ }^{11}$ It is thus irrelevant whether only the government or both, the government and the investor observe $\theta_{1}$. For the investor, what counts is the regulatory standard $s_{1}$ that she must comply with and the entry subsidy $\Sigma$ offered to her and that the government cannot commit to any regulatory policy for period two.
} 
$\theta_{2}$ is a stochastic variable, distributed according to a cumulative distribution function $G(\theta)$ on the domain $[\underline{\Theta}, \bar{\Theta}]$. We assume that $\theta_{1}<\bar{\Theta}$ so that there is a positive probability of the government wanting to raise the regulatory standard in period two ${ }^{12}$ Importantly, the realization of this variable is revealed to the government, but cannot be verified by a third party ${ }^{13}$ Therefore, the government cannot commit to a contingent level of period two regulation, and investor entry at the beginning of period one is thus subject to a hold-up problem.

The periodic profit of an investor depends on the stringency of the regulatory standard: $\pi_{t}=\pi\left(s_{t}\right)$, with $-\infty<\pi^{\prime}\left(s_{t}\right)<0$ and $\pi^{\prime \prime}\left(s_{t}\right) \leq 0$. Thus, the marginal harm that regulation inflicts upon the investor increases with the regulatory standard. All potential investors share the same profit function $\pi(\cdot)$. At the time of entry, profits in period one are certain, since $s_{1}$ has already been set, but profits in period two are subject to an uncertain regulatory standard which will not be set until period two. Investors form rational expectations about period two regulation and decide upon entry based on expected profits over both periods. Before deciding on investment, each potential investor draws an idiosyncratic entry cost $\phi$ from a cumulative distribution function $F(\phi)$ with density $f(\phi):=F^{\prime}(\phi)$ on the domain $[\underline{\phi}, \infty]$. An investor enters if expected profits outweigh the entry cost $\phi$, net of the entry subsidy.

The operating profit function $\pi\left(s_{t}\right)$ is known to the host government. There is a positive spillover from foreign investment to the domestic economy, say through vertical linkages with local suppliers or higher wages paid to domestic workers ${ }^{14}$ and possibly through an increase in domestic tax revenues. We abstain from any detailed modeling of these

\footnotetext{
${ }^{12}$ Our model can also accommodate a political economy approach in which $\theta_{t} v\left(s_{t}\right)$ is not domestic welfare, but the government's objective function and $\theta_{2}$ is subject to political shocks as in Beshkar et al. (2015) or Maggi and Staiger (2015). In this case, a positive $\theta$-shock is the result of a change in the political environment that asks for more regulation.

${ }^{13}$ This is in line with the US model BIT (bilateral investment treaty), which allows for postestablishment tightening of investment-related regulations under certain exceptions but assumes that a host country's "invocation and application of the exception will be difficult or perhaps impossible for an investor to challenge in arbitration"; see Poulsen et al. (2015, p. 144).

${ }^{14}$ There is ample evidence for such spillovers; see Blomström and Koko (1998), Görg (2007), Navaretti and Venables (2006, chapters 3 and 4) and OECD (2008).
} 
effects, but simply assume that they can be represented by a periodic stream $\alpha \pi\left(s_{t}\right)$, with $0<\alpha<1$. The government weighs the above benefits from regulation against the loss of such spillover effects caused by $\pi^{\prime}\left(s_{t}\right)<0$. In addition to regulation $s_{1}$ and $s_{2}$, the government grants an entry subsidy, denoted by $\Sigma$. We assume that the fixed entry cost $\phi$ is private information of the foreign investor, hence $\Sigma$ must be granted uniformly to all investors willing to enter. However, the government does know the distribution function $F(\phi)$. The government then sets the period one regulatory standard as well as the entry subsidy in a subgame-perfect fashion.

A number of comments on our modeling strategy are in order. First, allowing the domestic country to attract foreign firms also with a subsidy is in line with common practice of developed countries. Moreover, as we shall see below, it allows us to clearly identify the hold-up problem 15 Second, we employ a model of regulatory uncertainty because this is what ISDS provisions are supposed to deal with. The hold-up problem would also materialize if $\theta_{2}$ were deterministic, but ISDS provisions make sense only if $\theta_{2}$ and $s_{2}$ are both uncertain. Third, we assume that the entry cost and not the productivity of the investor is private information. Otherwise, our model would not provide a clear benchmark in terms of regulation and entry distortions because ISDS may change the incentive to attract high productivity investors ${ }^{16}$ Fourth, we also do not consider strategic interactions among firms. The strategic trade policy literature has shown that the policy incentives in an environment of strategic interactions among firms crucially depend on the assumed market structure, on whether firms compete with strategic substitutes or strategic complements and on whether they also serve their own country and the countries of their competitors or a third country only (see, for example, Markusen and Venables, 1988). None of this is considered here since we want to squarely focus on the welfare

\footnotetext{
${ }^{15}$ Under the Agreement on Subsidies and Countervailing Measures of the WTO, our entry subsidy would qualify as an actionable subsidy. Actionable subsidies are not prohibited, but can be challenged if they cause adverse effects. We allow the use of subsidies as we do not see the direct adverse effects for other countries, and the equivalent of a subsidy could be easily provided in form of any other assistance.

${ }^{16}$ If the productivity were private information, we would have to make further assumptions on the informational structure of the game, in particular, if and when the government and the ISDS panel may learn the investor's productivity.
} 
channels relevant for investor protection ${ }^{17}$

\subsection{Equilibrium without investment agreement}

We first consider an equilibrium where no ISDS exists, and we solve the model through usual backward induction. Upon learning about the realization of $\theta_{2}$ at the beginning of period two, the domestic government maximizes $\alpha \pi\left(s_{2}\right)+\theta_{2} v\left(s_{2}\right)$, leading to a regulation level $s_{2}^{*}\left(\theta_{2}\right)$ implicitly determined by the first-order condition ${ }^{18}$

$$
\alpha \pi^{\prime}\left(s_{2}^{*}\right)+\theta_{2} v^{\prime}\left(s_{2}^{*}\right)=0
$$

Note that from a global perspective $s_{2}^{*}\left(\theta_{2}\right)$ is suboptimally large since the government ignores second-period investor profits $\pi\left(s_{2}\right)$, taking account only of the externality $\alpha \pi_{2}\left(s_{2}\right)$. Knowing the distribution function of $\theta_{2}$, all potential investors correctly anticipate - in expected value terms - the government's regulatory policy. Using a caret to denote expected values, expected second-period profits are $\hat{\pi}_{2}=\int_{\underline{\Theta}}^{\bar{\Theta}} \pi\left[s_{2}^{*}(\theta)\right] \mathrm{d} G(\theta)$. Similarly, using $R_{2}$ to denote the welfare gains from period two regulation, we have $\hat{R}_{2}=\int_{\Theta}^{\bar{\Theta}} \theta v\left[s_{2}^{*}(\theta)\right] \mathrm{d} G(\theta)$.

In the first period, the government sets both the standard $s_{1}$ and the entry subsidy $\Sigma$. An investor with entry cost $\phi$ will enter if $\pi\left(s_{1}\right)+\hat{\pi}_{2}+\Sigma-\phi \geq 0$. The domestic government therefore maximizes $F(\bar{\phi})\left[\alpha\left[\pi\left(s_{1}\right)+\hat{\pi}_{2}\right]+\theta_{1} v\left(s_{1}\right)+\hat{R}_{2}-\Sigma\right]$ with respect to $s_{1}$ and $\Sigma$, subject to the participation constraint $\Sigma=\bar{\phi}-\left[\pi\left(s_{1}\right)+\hat{\pi_{2}}\right]$. Under the assumptions made, the constraint will be binding, hence this maximization problem is equivalent to maximizing expected domestic welfare

$$
W\left(s_{1}, \phi\right)=F(\bar{\phi})\left[(1+\alpha)\left[\pi\left(s_{1}\right)+\hat{\pi}_{2}\right]+\theta_{1} v\left(s_{1}\right)+\hat{R}_{2}-\bar{\phi}\right]
$$

\footnotetext{
${ }^{17}$ We also do not consider domestic consumer surplus explicitly because it is part of domestic welfare $v(\cdot)$ or not affected if the firms under consideration produce for a third market.

${ }^{18}$ Throughout the paper, we assume that $a \pi^{\prime \prime}\left(s_{t}\right)+\theta_{t} v^{\prime \prime}\left(s_{t}\right)<0$ for all $\theta_{t}$ and $s_{t}$, and for all $a \in[\alpha, 1+\alpha]$, whence the first-order condition will also be sufficient. Furthermore, we assume that $a \pi^{\prime}(0)+\theta_{t} v^{\prime}(0)>0$ so that $s_{t}^{*}>0$.
} 
with respect to $s_{1}$ and $\bar{\phi}$, where $\bar{\phi}$ is the threshold level of the entry cost. Expression (2) nicely demonstrates the two relevant distortions in our model. Due to the participation constraint, the government seemingly maximizes global welfare, i.e., the sum of all profits plus spillovers and regulation benefits, minus the entry cost. However, the domestic government cannot commit to an optimal level of second-period regulation vis à vis foreign investors, which is the implication of the hold-up problem and the key rationale underlying investor protection. The second distortion is that the government takes only the profit of the marginal entrant into account, but not of all entrants. Maximization of (2) yields the first-order conditions

$$
\begin{aligned}
(1+\alpha) \pi^{\prime}\left(s_{1}^{*}\right)+\theta_{1} v^{\prime}\left(s_{1}^{*}\right) & =0, \\
f\left(\bar{\phi}^{*}\right)\left[(1+\alpha)\left[\pi\left(s_{1}^{*}\right)+\hat{\pi}_{2}\right]+\theta_{1} v\left(s_{1}^{*}\right)+\hat{R}_{2}-\bar{\phi}^{*}\right]-F\left(\bar{\phi}^{*}\right) & =0,
\end{aligned}
$$

where we again use starred symbols to indicate optimal values. Remember that the idiosyncratic entry cost $\phi$ is private information. Hence, the government cannot administer $\bar{\phi}^{*}$ directly, but will simply set the entry subsidy at $\Sigma^{*}=\bar{\phi}^{*}-\left(\pi\left(s_{1}^{*}\right)+\hat{\pi}_{2}\right){ }^{19}$ Due to the participation constraint, $s_{1}^{*}$ is first best, but $\bar{\phi}^{*}$ is not. The government chooses $\bar{\phi}^{*}$ such that the marginal entrant's expected marginal welfare contribution is equal to the marginal expected cost of attracting this entrant.

We now compare these first-order conditions describing the government's behavior with two benchmarks. The first is the complete contract policy which allows the government to commit to a second-period regulation scheme $s_{2}\left(\theta_{2}\right)$, thereby solving the hold-up problem as it is equivalent to assuming complete contracts. Comparing the above policy with this benchmark seems useful as it isolates the detrimental effects of the incentive problem that ISDS mechanisms are meant to address. Note that a complete contract policy defined in this way is still subject to the constraint that the policy maker does not know the

\footnotetext{
${ }^{19}$ The second-order condition requires that $W\left(s_{1}, \phi\right)$ be concave in $s_{1}$ and $\phi$. Note that the second-order derivative with respect to $s_{1}$ is negative by the assumptions about $\pi(\cdot)$ and $v(\cdot)$ introduced above, while the cross-derivative is zero. Therefore, concavity requires that $f^{\prime}(\phi)\left(\Omega^{*}-\phi\right)-2 f(\phi)<0$, where $\Omega^{*}$ indicates the optimal value of profits plus spillovers plus regulation benefits. Morevover, we assume that $\bar{\phi}^{*}>\underline{\phi}$, guaranteeing an interior solution. If $\bar{\phi}^{*}<\underline{\phi}$, the hold-up problem would not affect entry.
} 
investor's idiosyncratic entry cost. The second benchmark is the first best, i.e., global welfare maximization where a social planner also takes into account profits as well as entry costs of all entrants. We find:

Proposition 1. Absent any ISDS or national treatment provision, the regulatory standard $s_{1}^{*}$ is first best, but the entry level $\bar{\phi}^{*}$ is suboptimally low compared to the complete contract policy, and the entry level of the complete contract policy is smaller than its first-best level.

Proof. See Appendix A.1.

The intuition for suboptimally low entry is that, due to the lock-in nature of investment, the government has no incentive to take into account investor profits when deciding about regulation in period two: it will set $s_{2}^{*}>s_{1}^{*}$ even if $\theta_{2}=\theta_{1}$. The participation constraint forces the government to take into account the period two profit of the marginal entrant when deciding about the subsidy in period one, but when doing so it anticipates low investor profits as following from its own overregulation in period two. Thus, the government attaches a value to firm entry that is too low, compared to the benchmark of complete contracts.

Why is the first-period regulation $s_{1}^{*}$ efficient, whereas the second-period regulation is not? Note, first, that $s_{1}^{*}$ is chosen prior to entry, and the entry constraint makes the government take into account foreign investor profits, in addition to the spillover $\alpha \pi\left(s_{1}\right)$. And secondly, world welfare is strictly additive in the two periodic regulation levels $s_{1}$ and $s_{2}$. Hence, overregulation in period two does not get in the way of choosing an efficient level of regulation in period one. Conversely, an efficient level of regulation in period one does not prevent the government from choosing an entry subsidy which is suboptimally low, the reason being that an entering firm's contribution to world welfare depends on regulation in both periods and overregulation in period two implies that this contribution is not fully internalized by the government.

In addition to caring about foreign investor's profits also in the second period, a social planner differs from our government in two further ways. First, the planner cares about the entry cost of investors. And secondly, she treats the subsidy cost as a mere transfer 
between the domestic government and foreign investors. However, the planner is subject to the same informational constraint as the government regarding the individual investor's entry cost $\phi$. As a result, she is constrained to using a uniform entry subsidy. Obviously, the planner is not subject to any hold-up problem and will thus choose an efficient level of regulation in period two as well as an entry level higher than $\bar{\phi}^{*}$. Since the subsidy cost is now a mere transfer, the first-best entry level is even larger than in the complete contract case.

It is worth emphasizing that the hold-up problem causes a suboptimally low level of entry compared to the complete contract policy despite the entry subsidy. Furthermore, even if the government could commit to follow the first-best regulation in the second period, a higher second-period regulatory standard would still follow if $\theta_{2}>\theta_{1}$. Indeed, a domestic firm would exactly face this risk, but it knows that the government takes domestic profits into account when deciding about regulation. In contrast, a foreign firm knows that its activities count only as far as the spillover effect is concerned 20 It should also be clear that any measure that mitigates the hold-up problem and increases domestic welfare by increasing entry will also increase global welfare, as an increase in entry must imply that all foreign investors realize larger expected profits, and not only the marginal investor, but all foreign investors will also be better off.

The first-best benchmark of Proposition 1 is comparable to what Maggi and Staiger (2015) call the maximum joint surplus, achievable under costless ex post transfers in renegotiating trade agreements between two countries facing ex ante uncertainty about the values of trade policies and lack of ex post verifiability of these values. With costless crosscountry transfers to compensate countries for a loss from the other country's trade policy, the first best is achievable. If transfers are costly, it is not. They introduce transfer costs and determine the design of optimal agreements between two countries that maximize the ex ante joint surplus, allowing for costly transfers. In our case, renegotiation is ruled

\footnotetext{
${ }^{20}$ Maskin and Tirole (1999) have shown that a unilateral hold-up problem can be solved if both parties can credibly make an agreement with a third party (an arbitrator) that does not have to rely on the third party knowing and being able to verify the true $\theta_{2}$. However, recent ISDS provisions do not include a third party. See Stähler (2019) for the design of an optimal ISDS provision that includes a third party.
} 
out by virtue of investment being locked in, and due to lack of verifiability of the value of regulation, the domestic country can neither commit to a complete contract policy nor to a first-best policy. Moreover, in contrast to Maggi and Staiger (2015), we are not determining a contract or agreement that maximizes the ex ante expected aggregate welfare. As we will show, ISDS provisions have little in common with dispute settlement mechanisms in international trade. Therefore, we are investigating whether an investorstate dispute settlement (ISDS) of the type considered in recent international agreements is able to reduce the hold-up-induced inefficiency.

\section{Investor-state dispute settlement (ISDS)}

\subsection{ISDS in investment agreements}

How do investment agreements deal with the hold-up problem? We observe that these agreements do not directly specify the regulatory policies that host countries of foreign investment are supposed to pursue. Instead, they feature indirect means of tackling the inefficiency described above. The first is to install an investor-state dispute settlement (ISDS) mechanism, the other is to impose a national treatment restriction on government policies. The common element of both approaches is that they want the host government to internalize the externality effect that its regulatory policy has on foreign investors.

An ISDS mechanism tries to achieve this by imposing the threat that a special tribunal, which we will refer to as a panel, may decide that the government has to pay a compensation to a foreign investor for profit losses due to regulatory changes ${ }^{21}$ Of course, any ISDS panel will not be in the position to observe $\theta_{2}$, the welfare-value of domestic regulation. If it were, this would amount to verifiability of $\theta_{2}$, and the hold-up problem would not arise in the first place. Note the two key ideas relating to compensation: The

\footnotetext{
${ }^{21}$ Article 9.29 of the TPP draft (2016) specifies that "the tribunal may award (...) only: (a) monetary damages and any applicable interest; and (b) restitution of property, in which case the award shall provide that the respondent may pay monetary damages and any applicable interest in lieu of restitution."
} 
first is that it takes place through direct monetary payments to the foreign investor, but not to domestic investors. The second is that compensations are based on profit losses due to policy change. Thus, the ISDS procedure is not triggered by breach of any contractual obligation, but simply by regulation causing a loss in profits. Within our model this boils down to $s_{2}>s_{1}$ since profits depend monotonically on $s$.

The TPP draft exhibits these features very clearly. In particular, Article 9.8 of the draft agreement specifies that "[n]o Party shall expropriate or nationalize a covered investment either directly or indirectly through measures equivalent to expropriation or nationalization (expropriation) except: (a) for a public purpose; (b) in a non-discriminatory manner; (c) on payment of prompt, adequate and effective compensation ...; and (d) in accordance with due process of law."22 Arguably, any change in regulation leading to a profit decrease potentially qualifies as a measure equivalent to expropriation. In some areas of regulatory policy, the law explicitly provides for so-called "police powers carve-outs" (PPCAs), rules specifying conditions under which the regulator is exempt from paying compensation, typically based on the social benefits of regulation; see Blume et al. (1984) and Aisbett et al. (2010a). However, the TPP agreement draft conspicuously does not define any such PPCAs 23

How do these ISDS provisions compare to provisions in trade agreements? There is a small recent body of literature that analyzes liability rules as a means to deal with inefficiencies of trade policies that arise from exactly the same conditions that cause inefficiency in international investment: ex ante uncertainty about the true value of the policy in question and non-verifiability of this true value of the policy by third parties. In trade agreements, a liability rule gives a party the option of escaping from its free trade obligation in exchange for the liability to compensate the other party for any damage done by this change in policy. In other words, it may "buy itself out" of the free trade obligation

\footnotetext{
${ }^{22}$ Interestingly, Article 9.8 uses nearly the same wording as Article 2.1 of the draft of the Multilateral Agreement on Investment (MAI), see MAI draft (1998). MAI was a multilateral OECD initiative for foreign investment protection that failed to be adopted.

${ }^{23}$ Article 29.5 on the tobacco industry (see also footnote 35 and the chapters on environmental cooperation and labor standards do not qualify as PPCAs.
} 
at conditions specified in the agreement. Importantly, the underlying assumption is that the liability rule as such is perfectly enforceable.

Liability rules may vary greatly in detail, particularly regarding the role assigned to a dispute settlement body (DSB) and the type and accuracy of ex post information available to that body ${ }^{24}$ Part of this literature develops an optimal schedule that maximizes the expected joint payoff. Other papers discuss whether or not (or under what conditions) a certain type of a priori plausible DSB behavior will be able to reduce potential inefficiencies. In this paper, we adopt this second approach, and - in line with much of the literature - we assume that the panel acts upon receiving a noisy signal for the true welfare value of domestic regulation. Moreover, we additionally ask whether such a liability-type ISDS mechanism is dominating (or dominated by) the alternative institutional setup of a national treatment provision.

The trade literature often assumes the possibility of renegotiation after the uncertainty about the policy evaluation is resolved, and before a dispute is brought before the DSB. This makes sense only in the context of trade agreements where there are clear policy obligations to be negotiated about, but investment agreements typically do not include specific policy obligations. Furthermore, investment may be irreversible when the uncertainty is resolved, hence the investor has nothing to bargain about whereas the government still gets to choose its policy. In the present context, the analogue of renegotiation, or early settlement, is regulatory chill that avoids triggering compensation; see Janeba (2019). However, since it internalizes the externality effect of regulation, the regulatory chill of a well-functioning ISDS mechanism should increase welfare. Moreover, the regulatory chill effect does not imply that panel rulings are only an off-equilibrium threat. They will be observed also as an equilibrium outcome, since accepting such a ruling may be an efficient way for the host country government to react to a change in the policy environment ${ }^{25}$

\footnotetext{
${ }^{24}$ For instance, in Maggi and Staiger (2015) the DSB has no interesting role to play in implementing the rule, it simply enforces a non-contingent level of damages to be compensated. In contrast, Maggi and Staiger (2011), Beshkar (2016) and Maggi and Staiger (2018) assume that the DSB acts upon receiving a noisy signal about the welfare-value of the escape option (protection) to the countries in question and determines the level of damages depending on this signal.

${ }^{25}$ Furthermore, in the context of trade policy, compensation takes the form of a retaliatory policy
} 


\subsection{Modeling ISDS}

Our reading of ISDS provisions leads to two key observations that guide our modeling of ISDS. First, the panel will not play the role of a mere arbitrator, but any effective ISDS mechanism will authorize the panel to issue a binding verdict ${ }^{26}$ Second, there will be substantial discretion in how the panel rules on a dispute over "expropriation", and consequently from an ex ante perspective the panel ruling will be stochastic. We assume that any given realization of $\theta_{2}$, observed only by the government, generates a noisy signal $\tilde{\theta}_{2}$ with a distribution function $H_{\theta_{2}}\left(\tilde{\theta}_{2}\right)$. Furthermore, we assume this signal to be undistorted, so that $\int_{0}^{\infty} \tilde{\theta}_{2} \mathrm{~d} H_{\theta_{2}}\left(\tilde{\theta}_{2}\right)=\theta_{2}$, and both the panel and the government to have full knowledge of the distribution function(s) $H_{\theta_{2}}\left(\tilde{\theta}_{2}\right)$.

The panel will be called upon if and only if $s_{2}>s_{1}$ so that investors suffer from a profit loss in period two compared to period one. The information set of the panel includes the observed levels of regulation, $s_{1}$ and $s_{2}$, as well as the signal $\tilde{\theta}_{2}$. Since all agents are assumed risk-neutral, the behavior of investors and the government is driven by the expected compensation awarded by the panel, which we denote by $T$. The expected compensation, conditional on $\theta_{2}$ is given by

$$
\begin{gathered}
T\left(s_{1}, s_{2}, \tilde{\theta}_{2}, \rho\right)= \begin{cases}\mathbb{E}\left[\mu\left(\tilde{\theta}_{2}, s_{1}, s_{2}\right) \mid \theta_{2}\right] \rho\left[\pi\left(s_{1}\right)-\pi\left(s_{2}\right)\right] & \text { if } s_{2}>s_{1}, \\
0 & \text { otherwise, }\end{cases} \\
\text { where } \quad \mu(\cdot) \geq 0, \partial \mu(\cdot) / \partial \tilde{\theta}_{2} \leq 0, \partial \mu(\cdot) / \partial s_{1} \leq 0, \partial \mu(\cdot) / \partial s_{2} \geq 0 .
\end{gathered}
$$

In this specification, the function $\mu(\cdot)$ describes the panel's evaluation of the extent to

adopted by the party harmed by protection, as is typical for GATT/WTO safeguard procedures, implying a deadweight loss (see Maggi and Staiger, 2015, 2018). In the investment context, such retaliatory policies are ruled out by construction since the party to be compensated is a private investor. Hence, compensation will almost always take place through direct monetary transfers.

${ }^{26}$ This does not rule out that the agreement provides for a due process where the government may file an appeal. However, filing an appeal is much different from simply rejecting an arbitrated solution. See Beshakr (2016) for the difference between an "arbitrated liability rule" and what he calls a "directrevelation mechanism". A direct revelation mechanism determines an enforceable outcome from whatever information the DSB has available at the time of ruling. Our modeling of the ISDS mechanism corresponds to the "direct-revelation mechanism." 
which $s_{2}$ is justifiable, given the previous period regulation $s_{1}$, and given the signal $\tilde{\theta}_{2}$. The higher the value of $\mu(\cdot)$, the higher the likelihood of the panel deciding in favor of the investor. Note that the signaling process is specific to the realization of $\theta_{2}$ which is, however, unknown to the panel. The expected value of $\mu(\cdot)$, conditional on $\theta_{2}$, is

$$
\mathbb{E}\left[\mu\left(\tilde{\theta}_{2}, s_{1}, s_{2}\right) \mid \theta_{2}\right]=\int_{0}^{\infty} \mu\left(\tilde{\theta}_{2}, s_{1}, s_{2}\right) \mathrm{d} H_{\theta_{2}}\left(\tilde{\theta}_{2}\right)
$$

The partial derivatives of $\mu(\cdot)$ given in (4) may be rationalized as representing a panel that exploits the signal $\tilde{\theta}_{2}$ in a theory-consistent way. From the panel's perspective, any given regulation $s_{2}>s_{1}$ represents an implicit claim by the government that tightening regulation in period two is justified by new fundamentals, i.e., a correspondingly high value of $\theta_{2}$. In order to exploit the information from the signal $\tilde{\theta}_{2}$, the panel calculates the upper and lower bound, respectively, of an interval of hypothetical $\theta_{2}$-values that would make the observed regulatory level $s_{2}$ consistent with the structural characteristics of the economy. The upper bound of this interval is given by

$$
\check{\theta}\left(s_{2}\right):=-\frac{(1+\alpha) \pi^{\prime}\left(s_{2}\right)}{v^{\prime}\left(s_{2}\right)}
$$

This is the level of $\theta_{2}$ that would prompt a social planner caring about world welfare to choose the exact same $s_{2}$ as set by the government. Assuming $\theta_{2}=\check{\theta}\left(s_{2}\right)$ the panel would therefore see no reason to grant compensation to the investor. Obviously, assuming $\theta_{2}>\check{\theta}\left(s_{2}\right)$ would be inconsistent, given the government has chosen $s_{2}$. But $\theta_{2}$ may well be below $\check{\theta}\left(s_{2}\right)$, meaning that in choosing $s_{2}$ the government attaches less than full weight to foreign profits. At the lower bound, we have

$$
\underline{\theta}\left(s_{2}\right):=-\frac{\alpha \pi^{\prime}\left(s_{2}\right)}{v^{\prime}\left(s_{2}\right)}<\check{\theta}\left(s_{2}\right)
$$

Assuming $\theta_{2}=\underline{\theta}\left(s_{2}\right)$ the panel would conclude that the choice of $s_{2}$ reflects fully opportunistic government behavior, ignoring all foreign profits and taking into account only the spillover $\alpha \pi$. In this case it would obviously see reason to grant compensation. From the 
above assumptions, we have $\check{\theta}^{\prime}\left(s_{2}\right)>0$ as well as $\underline{\theta}^{\prime}\left(s_{2}\right)>0$.

How can the panel use the information incorporated in $\underline{\theta}\left(s_{2}\right)$ and $\check{\theta}\left(s_{2}\right)$ in order to evaluate whether the government's choice of $s_{2}$ is justified? To see this, suppose the distribution function $H_{\theta_{2}}\left(\tilde{\theta}_{2}\right)$ is uniform, with density $1 / 2 \epsilon$ around the true realization of $\theta_{2}$. Then, the probability of the signal taking on a value equal to $\tilde{\theta}_{2}$ or lower, conditional on $\theta_{2}$, is given by ${ }^{27}$

$$
H_{\theta_{2}}\left(\tilde{\theta}_{2}\right)=\frac{\tilde{\theta}_{2}-\theta_{2}+\epsilon}{2 \epsilon}
$$

Moreover, suppose that - when judging the degree of opportunism behind the government's choice of $s_{2}$ - the panel employs a type-I-error calculation against the hypothesis that the government acts like a social planner maximizing world welfare, with zero opportunism. If this hypothesis is true, then the probability of receiving a signal equal to, or lower than, $\tilde{\theta}_{2}$, is equal to

$$
H_{\check{\theta}\left(s_{2}\right)}\left(\tilde{\theta}_{2}\right)= \begin{cases}\frac{\tilde{\theta}_{2}-\check{\theta}\left(s_{2}\right)+\epsilon}{2 \epsilon} & \text { if } \check{\theta}\left(s_{2}\right)-\epsilon<\tilde{\theta}_{2}<\check{\theta}\left(s_{2}\right)+\epsilon \\ 0 & \text { if } \tilde{\theta}_{2}<\check{\theta}\left(s_{2}\right)-\epsilon \\ 1 & \text { if } \tilde{\theta}_{2}>\check{\theta}\left(s_{2}\right)+\epsilon\end{cases}
$$

This is the probability of erroneously concluding from the signal $\tilde{\theta}_{2}$ that the government's behavior involves at least some degree of opportunism, if the government were in fact acting like a social planner. If this probability is equal to zero, then in the eyes of the panel the government has zero credibility as a global welfare maximizer. Conversely, if $H_{\breve{\theta}\left(s_{2}\right)}\left(\tilde{\theta}_{2}\right)=1$, then the government has perfect credibility in claiming that it acts in the interest of global welfare; the likelihood of a type-I-error in rejecting this hypothesis is equal to one.

Given the interval $\left[\underline{\theta}\left(s_{2}\right), \check{\theta}\left(s_{2}\right)\right]$, the highest possible value of the signal is $\check{\theta}\left(s_{2}\right)+\epsilon$ while the lowest possible value is $\underline{\theta}\left(s_{2}\right)-\epsilon$. Inserting, we obtain $H_{\check{\theta}\left(s_{2}\right)}\left[\check{\theta}\left(s_{2}\right)+\epsilon\right]=1$,

\footnotetext{
${ }^{27}$ In this sense, the signal allows a Bayesian update on the probability that regulation $s_{2}$ conforms with the claimed $\theta_{2}$. Without signal, any claim that $s_{2}$ is due to $\theta_{2}=\check{\theta}\left(s_{2}\right)$ can be justified.
} 
$H_{\check{\theta}\left(s_{2}\right)}\left[\underline{\theta}\left(s_{2}\right)-\epsilon\right]<0$, and for $\tilde{\theta}_{2} \in\left(\check{\theta}\left(s_{2}\right)-\epsilon, \check{\theta}\left(s_{2}\right)+\epsilon\right)$ we have $0<H_{\check{\theta}\left(s_{2}\right)}\left(\tilde{\theta}_{2}\right)<1$. Thus, the possible range of signal values falls into two parts. There will always be a non-empty lower range of signal-values for which the panel concludes - with full confidence - some degree of opportunism on the part of the government. Moreover, provided that the signal is imprecise, i.e., $\epsilon>0$, there is a non-empty upper range of signal values for which the likelihood of a type-I-error in rejecting the hypothesis of zero opportunism is larger than zero but lower than one, and increasing in $\tilde{\theta}_{2}$. And finally, the case where this likelihood is equal to one arises only for the highest possible signal value $\check{\theta}\left(s_{2}\right)+\epsilon$.

Thus, under a uniform distribution $H_{\theta_{2}}\left(\tilde{\theta}_{2}\right)$ for $\tilde{\theta}_{2} \in\left[\underline{\theta}\left(s_{2}\right), \check{\theta}\left(s_{2}\right)\right]$, the probability of correctly inferring some degree of opportunism from the government's choice of $s_{2}$ now emerges as

$$
1-H_{\check{\theta}\left(s_{2}\right)}\left(\tilde{\theta}_{2}\right)=\min \left\{1, \frac{\check{\theta}\left(s_{2}\right)-\tilde{\theta}_{2}+\epsilon}{2 \epsilon}\right\},
$$

It is straightforward to see that, starting out from interior probability values, this probability falls with any increase in the signal value $\tilde{\theta}_{2}$ while rising in $s_{2}$. In the specification of expected compensation in (4) above, $\mu(\cdot)$ was interpreted as the likelihood of the panel deciding in favor of the investor. A possible specification would now be to set this equal to $1-H_{\check{\theta}\left(s_{2}\right)}\left(\tilde{\theta}_{2}\right)$. Clearly, the conditions on $\mu(\cdot)$ formulated in (4) are satisfied for the uniform distribution underlying the right-hand side of (9). In this particular case, since the signal is unbiased, we would have $\mathbb{E}\left[\mu\left(\tilde{\theta}_{2}, \cdot\right) \mid \theta_{2}\right]=\left[\check{\theta}\left(s_{2}\right)-\theta_{2}\right] / 2 \epsilon+1 / 2$.

We want to stress, however, that the plausibility of our approach in (4) above extends beyond the confines of the uniform distribution for $H_{\theta_{2}}$. Thus, our specification in (4) allows the panel to be sensitive to $s_{1}$ as well as to $s_{2}$. A plausible interpretation would be that when judging the government's regulatory policy the panel is more likely to conclude opportunism if the policy change as such is large. This reinforces $\partial \mu(\cdot) / \partial s_{2}>0$, and it additionally means that $\partial \mu(\cdot) / \partial s_{1}<0$ as well as $\partial \mathbb{E}\left[\mu\left(\tilde{\theta}_{2}, \cdot\right) \mid \theta_{2}\right] / \partial s_{1} \leq 0$. However, none of the results below depend on the inequalities in (4) to be strict inequalities. Indeed, our model even accommodates ISDS proceedings to be somewhat of a "black box", such that $\mu(\cdot)$ is fixed or depends only on $s_{1}$ and/or $s_{2}$ as specified in (4), even absent any signal $\tilde{\theta}_{2}$. 
If $\mu(\cdot)$ measures the likelihood of the panel awarding damage to the investor, the parameter $\rho$ measures the extent to which the profit loss $\pi\left(s_{1}\right)-\pi\left(s_{2}\right)$ effectively gets translated into the amount of damage awarded. The magnitude of $\rho$ may differ among agreements, and this specification allows us to evaluate the impact of ISDS provisions as such by considering changes of $\rho$ from $\rho=0$ (no ISDS) to $\rho>0$ (ISDS). In addition, the magnitude of $\rho$ may also vary between different cases under any given agreement. While the regulation levels $s_{1}$ and $s_{2}$ should be easy for the panel to observe, the same is not necessarily true for profit levels. It is obvious that, given the ISDS mechanism, investors will have an incentive to over-report their profit losses. Since $\pi\left(s_{t}\right)$ denotes true profits, this would be captured by a high value of $\rho{ }^{28}$ We therefore allow $\mathbb{E}\left[\mu\left(\tilde{\theta}_{2}, s_{1}, s_{2}\right) \mid \theta_{2}\right] \rho$ to take on values above one.

\subsection{Equilibrium with ISDS}

The sequencing of decision making is as follows. At the beginning of period one, the host government sets the regulatory standard $s_{1}$ and offers an entry subsidy $\Sigma$, and foreign investors subsequently decide about entry. In period two, after observing $\theta_{2}$, the government sets $s_{2}$. If $s_{2}>s_{1}$, the ISDS panel is called in, receives the signal $\tilde{\theta}_{2}$ and decides on compensation. The key difference arising from ISDS is that the government's regulatory decision at the beginning of period two now depends on the regulatory standard set in period one, which is anticipated by the government when deciding about regulation in period one. Let

$$
W_{2}\left(s_{1}, s_{2}, \rho\right)= \begin{cases}\alpha \pi\left(s_{2}\right)+\theta_{2} v\left(s_{2}\right) & \text { if } s_{2} \leq s_{1} \\ \alpha \pi\left(s_{2}\right)+\theta_{2} v\left(s_{2}\right)-\mathbb{E}\left[\mu(\cdot) \mid \theta_{2}\right] \rho\left[\pi\left(s_{1}\right)-\pi\left(s_{2}\right)\right] & \text { if } s_{2}>s_{1}\end{cases}
$$

\footnotetext{
${ }^{28}$ It is well known from the literature on the taxation of multinational enterprises that it is relatively easy for an international investor to shift profits - and thus also profit losses - from one location to the other. For a recent quantitative review of the empirical literature on profit-shifting behavior of multinational firms, see Heckemeyer and Overesch (2017).
} 
denote the expected second-period domestic welfare. In period two, the government sets $s_{2}$ so as to maximize $W_{2}\left(s_{1}, s_{2}, \rho\right)$, taking into account the expected panel ruling. The first-order condition on the optimal value $s_{2}^{*}$ is

$$
\begin{array}{rlrl}
\alpha \pi^{\prime}\left(s_{2}^{*}\right)+\theta_{2} v^{\prime}\left(s_{2}^{*}\right) & =0 & \text { if } \theta_{2}<\bar{\theta}_{2}\left(s_{1}\right), \\
\alpha \pi^{\prime}\left(s_{2}^{*}\right)+\theta_{2} v^{\prime}\left(s_{2}^{*}\right)+\rho t\left(s_{1}, s_{2}^{*}, \theta_{2}\right)=0 & \text { if } \theta_{2} \geq \bar{\theta}_{2}\left(s_{1}\right),
\end{array}
$$

where

$$
\begin{aligned}
t\left(s_{1}, s_{2}^{*}, \theta_{2}\right) & :=\mathbb{E}\left[\mu(\cdot) \mid \theta_{2}\right] \pi^{\prime}\left(s_{2}^{*}\right)-\frac{\partial \mathbb{E}\left[\mu(\cdot) \mid \theta_{2}\right]}{\partial s_{2}}\left[\pi\left(s_{1}\right)-\pi\left(s_{2}^{*}\right)\right]<0 \\
\text { and } \quad \bar{\theta}_{2}\left(s_{1}\right) & :=-\frac{\alpha \pi^{\prime}\left(s_{1}\right)}{v^{\prime}\left(s_{1}\right)} .
\end{aligned}
$$

Note that $\rho t\left(s_{1}, s_{2}^{*}, \theta_{2}\right)$ measures the marginal effect of $s_{2}$ on expected domestic welfare through the expected compensation payments in cases where $\theta_{2} \geq \bar{\theta}_{2}\left(s_{1}\right){ }^{29}$ We use $s_{2}^{*}\left(\theta_{2}, s_{1}, \rho\right)$ to indicate the regulation level in the second period implicitly determined by (11), and we now scrutinize second-period welfare and regulation.

Lemma 1. For any given $s_{1}$ and $\theta_{2}$, introducing and tightening the ISDS mechanism lowers the government's choice $s_{2}^{*}$ and reduces the second-period domestic welfare, provided that $\theta_{2} \geq \bar{\theta}_{2}\left(s_{1}\right)$. For any given $\rho$ and $\theta_{2}$, an increase in $s_{1}$ weakly raises $s_{2}^{*}$.

Proof. $\mathrm{d} s_{2}^{*} / \mathrm{d} \rho=-t\left(s_{1}, s_{2}^{*}, \theta_{2}\right) / \partial^{2} W_{2} / \partial s_{2}^{2}<0$ due to the second-order condition and $t\left(s_{1}, s_{2}^{*}, \theta_{2}\right)<0 . \mathrm{d} W_{2}\left(s_{1}, s_{2}, \rho\right) / \mathrm{d} \rho=\partial W_{2}\left(s_{1}, s_{2}, \rho\right) / \partial \rho=t\left(s_{1}, s_{2}^{*}, \theta_{2}\right)<0$ due to the Envelope Theorem. $\mathrm{d} s_{2}^{*} / \mathrm{d} s_{1}=-\left[\rho \partial t\left(s_{1}, s_{2}^{*}, \theta_{2}\right) / \partial s_{1}\right] /\left[\partial^{2} W_{2} / \partial s_{2}^{2}\right]>0$ due to the secondorder condition and $\partial t\left(s_{1}, s_{2}^{*}, \theta_{2}\right) / \partial s_{1} \geq 0$ because $\partial \mu(\cdot) / \partial s_{1} \leq 0$ and $\pi\left(s_{1}\right)-\pi\left(s_{2}\right)>$ 0 .

A number of comments are in order. First, the ISDS provision implicitly defines a

\footnotetext{
${ }^{29}$ For low values of $\theta_{2}<\bar{\theta}_{2}\left(s_{1}\right)$, the second-order condition is satisfied since by assumption $\pi^{\prime \prime}(\cdot)<$ 0 , and for high values of $\theta_{2} \geq \bar{\theta}_{2}\left(s_{1}\right)$ the second-order condition is satisfied by the assumption that $\partial^{2} \mu(\cdot) / \partial s_{2}^{2} \geq 0$, which implies a non-decreasing marginal effect of $s_{2}$ on the likelihood of the panel awarding compensation.
} 
threshold value for the second-period realization of $\theta_{2}$. For any $\theta_{2}>\bar{\theta}_{2}\left(s_{1}\right)$, the government will set $s_{2}^{*}>s_{1}$, thus initiating a panel ruling. Consequently, ISDS panel rulings are an equilibrium outcome. A more stringent regulation in period one increases this threshold as $\bar{\theta}_{2}\left(s_{1}\right)$ increases with $s_{1}$. Second, for any $\theta_{2} \geq \bar{\theta}_{2}\left(s_{1}\right)$, period two regulation will increase with $s_{1}$ as well, because the panel will be more likely to reject an investor's claim if the previous regulation level was already large to begin with. Both the increase of $\bar{\theta}_{2}\left(s_{1}\right)$ and the increase of $s_{2}^{*}$ with $s_{1}$ demonstrate the intertemporal regulation effect of ISDS: a larger regulatory level $s_{1}$ buys more discretion for period two as it increases the threshold that defines the ISDS threat and reduces the expected compensation 30 Third, $s_{2}^{*}$ unambiguously decreases with $\rho$. Strengthening an ISDS provision raises the expected compensation for any given $s_{2}>s_{1}$, and the host government will therefore want to reduce this expected compensation by choosing a smaller $s_{2}^{*}$ for any value $\theta_{2} \geq \bar{\theta}_{2}\left(s_{1}\right)$. This is the way that "regulatory chill" appears in our environment, and it has an immediate consequence for domestic second-period welfare, as summarized by Lemma 1 above.

While it is obvious that a binding ISDS mechanism will reduce domestic welfare in the second period for a given $s_{1}$, it is not clear yet what it will do to overall domestic welfare and to global welfare. To see how ISDS affects overall welfare, we must investigate how it affects government behavior in the first period. As before, the first-period policy means setting both the standard $s_{1}$ and the entry subsidy $\Sigma$, whereby the government now takes into account that the first-period subsidy $s_{1}$ will affect the second-period policy, due to the ISDS mechanism as described above. We continue using a caret to denote expected second-period variables. In particular, we now have $\hat{\pi}_{2}\left(s_{1}, \rho\right)=\int_{\underline{\Theta}}^{\bar{\Theta}} \pi\left[s_{2}^{*}\left(\theta, s_{1}, \rho\right)\right] \mathrm{d} G(\theta)$ and $\hat{R}_{2}\left(s_{1}, \rho\right)=\int_{\Theta}^{\bar{\Theta}} \theta v\left[s_{2}^{*}\left(\theta, s_{1}, \rho\right)\right] \mathrm{d} G(\theta)$. In addition, the ex ante expected compensation is given by $\hat{T}:=\int_{\underline{\Theta}}^{\bar{\Theta}} \mathbb{E}\left[T(\cdot) \mid \theta_{2}\right] \mathrm{d} G(\theta)$; see 44$) 31$

Entry occurs if a potential investor with entry cost $\phi$ finds $\pi\left(s_{1}\right)+\hat{\pi}_{2}+\Sigma+\hat{T}-$ $\phi \geq 0$. Thus, the domestic government will maximize $F(\bar{\phi})\left[\alpha\left[\pi\left(s_{1}\right)+\hat{\pi}_{2}\right]+\theta_{1} v\left(s_{1}\right)+\right.$

\footnotetext{
${ }^{30}$ The first effect will still materialize if $\mu(\cdot)$ depends only on $s_{2}$ and $\tilde{\theta}_{2}$.

${ }^{31}$ Note that the expectation $\mathbb{E}\left[T(\cdot) \mid \theta_{2}\right]$ is taken with respect to the signal value $\tilde{\theta}_{2}$, which follows a stochastic process specific to the realization $\theta_{2}$.
} 
$\left.\hat{R}_{2}-\hat{T}-\Sigma\right]$ with respect to $s_{1}$ and $\Sigma$, subject to the participation constraint $\Sigma=$ $\bar{\phi}-\left[\pi\left(s_{1}\right)+\hat{\pi}_{2}+\hat{T}\right]$. As above, this maximization problem is equivalent to maximizing expected domestic welfare

$$
F(\bar{\phi})\left[(1+\alpha)\left[\pi\left(s_{1}\right)+\hat{\pi}_{2}\left(s_{1}, \rho\right)\right]+\theta_{1} v\left(s_{1}\right)+\hat{R}_{2}\left(s_{1}, \rho\right)-\bar{\phi}\right]
$$

with respect to $s_{1}$ and $\bar{\phi}$. In this expression, the expected compensation cancels out as an increase in expected compensation is equivalent to a decrease in the subsidy $\Sigma$ for given $s_{1}$ and $s_{2}$. It is thus important what ISDS does to entry and regulatory policies in both periods. The first-order conditions reveal that the government now takes into account an intertemporal dependency in regulation ${ }^{32}$

$$
\begin{aligned}
(1+\alpha)\left[\pi^{\prime}\left(s_{1}^{*}\right)+\frac{\partial \hat{\pi}_{2}\left(s_{1}^{*}, \rho\right)}{\partial s_{1}}\right]+\theta_{1} v^{\prime}\left(s_{1}^{*}\right)+\frac{\partial \hat{R}_{2}\left(s_{1}^{*}, \rho\right)}{\partial s_{1}}=0 \\
f\left(\bar{\phi}^{*}\right)\left[(1+\alpha)\left[\pi\left(s_{1}^{*}\right)+\hat{\pi}_{2}\left(s_{1}^{*}, \rho\right)\right]+\theta_{1} v\left(s_{1}^{*}\right)+\hat{R}_{2}\left(s_{1}^{*}, \rho\right)-\bar{\phi}^{*}\right]-F\left(\bar{\phi}^{*}\right)=0 .
\end{aligned}
$$

What is the effect of ISDS on regulation and welfare? We provide an answer to this question through a comparative static analysis of the above equilibrium for an exogenous variation in $\rho$. Increasing $\rho$ makes the ISDS mechanism stronger in that for any given set of values $s_{1}, s_{2}$ and $\theta_{2}$ that constitute a case for the ISDS panel in the first place, the expected compensation awarded by the panel is increasing. A marginal increase in $\rho$ from $\rho=0$ amounts to the introduction of an ISDS mechanism. In the following proposition, we compare the ISDS-ridden equilibrium with an equilibrium absent ISDS.

Proposition 2. An ISDS provision can lead to more or less regulation in the first period, and the domestic and global welfare changes are ambiguous in general. If $\rho$ is sufficiently small, ISDS leads to less stringent regulation (underregulation) in the first period as well as less stringent regulation in the second period, provided that $\theta_{2} \geq \bar{\theta}_{2}\left(s_{1}\right)$, and it leads to more investor entry. An ISDS provision generally increases (decreases) domestic and

\footnotetext{
${ }^{32}$ The second-order condition on $s_{1}$ is satisfied due to $\pi^{\prime \prime}(\cdot)<0$ and $v^{\prime \prime}(\cdot)<0$, together with $\mathrm{d} s_{2}^{*} / \mathrm{d} s_{1}>$ 0 ; see Lemma 1. The second-order condition on $\bar{\phi}$ again requires $f^{\prime \prime}(\phi)\left(\Omega^{*}-\phi\right)-2 f^{\prime}(\phi)<0$, where $\Omega^{*}$ is the optimal value of profits plus spillovers plus regulation benefits.
} 
global welfare, if and only if it leads to more (less) entry and vice versa.

Proof. See Appendix A.2.

Thus, a main conclusion of our analysis is that an ISDS mechanism aiming at indemnity payments may reduce the hold-up problem if $\rho$ is not too large. But it comes with the cost of a suboptimally low $s_{1}^{*}$ in contrast to the first-best $s_{1}$ without ISDS (see Proposition 1), a form of "regulatory chill". However, it pays for the government to bear the welfare cost of lower first-period regulation as an effective commitment to reduce overregulation in period two. At the same time, any adjustment to a large $\theta_{2}$-realization is not too costly if $\rho$ is small, and a reduction in second-period overregulation fosters entry, which is suboptimally low without ISDS ${ }^{33}$ In contrast, if $\rho$ is large, then the government may find paying the welfare cost of higher first-period regulation worthwhile, since this buys it some discretion for liability-free second-period regulation because the expected damage payments are reduced. In particular, we can show:

Lemma 2. For low initial levels of $\rho$, a further increase in $\rho$ leads to less stringent regulation in both periods. There exists a critical level $\tilde{\rho}>0$ where the marginal effect of $\rho$ on $s_{1}^{*}$ is zero while the marginal effect on $s_{2}^{*}$ is negative. If $s_{1}^{*}$ is convex in $\rho$ and a minimum exists, then a further increase in $\rho$ beyond $\tilde{\rho}>0$ will lead to more stringent first-period regulation, eventually leading to more stringent regulation in period one than would be the case without ISDS.

Proof. See Appendix A.2.

Since a larger $s_{1}^{*}$ makes entry less attractive, ISDS will reduce welfare in this case. It should be noted that the welfare effect of an ISDS provision ultimately depends what it does to the entry level.

Our specification (9) allows us to examine the effects of a change in the precision of the ISDS proceedings. An increase in precision, i.e., a lower $\epsilon$, means that the panel gets

\footnotetext{
${ }^{33}$ In this sense, ISDS serves as a commitment device as trade agreements do against domestic lobbying, see e.g. Maggi and Rodrígez-Clare (1998).
} 
a better idea whether the claimed necessity of $s_{2}>s_{1}$ is consistent with the true value of $\theta_{2}$. An increase in precision is equivalent to a decrease in $\epsilon$, and we find

Lemma 3. An increase in the precision of the signal $\epsilon$ is equivalent to an increase in $\rho$ and decreases second-period regulation.

Proof. This follows immediately from comparing (4) with the first-order condition (11), observing the role of $\epsilon$ in (9).

The intuition is that an increase in precision increases the probability that the panel agrees with the investor for a given $s_{2}$. Consequently, the government has an incentive to reduce second-period regulation. Since $\mathbb{E}\left[\mu\left(\tilde{\theta}_{2}, s_{1}, s_{2}\right) \mid \theta_{2}\right] \rho=\bar{\rho}\left(\check{\theta}\left(s_{2}\right)-\tilde{\theta}_{2}\right)+1 / 2$ where $\bar{\rho}=\rho / 2 \epsilon$, an increase in precision has similar welfare effects as an increase in $\rho$. If $\rho$ is sufficiently small, domestic welfare will increase with a decrease in $\epsilon$ as in Proposition 2 . However, it may imply an increase in first-period regulation and thus a welfare decrease if $\rho$ is large to begin with.

Finally, we can also explore the role of the spillover parameter $\alpha$ in an ISDS environment. Since $\alpha$ is a primitive in our model, we cannot make any claims in terms of welfare changes due to a change in $\alpha$, as a different $\alpha$ implies a different welfare specification. However, we can meaningfully examine how a stronger spillover affects the regulation levels $s_{1}^{*}$ and $s_{2}^{*}$. Intuitively, a stronger spillover mitigates the hold-up problem since the interests of the host country and the foreign investor become more aligned. In a laissez-faire world without ISDS, this leads to lower regulatory levels in both periods. Proposition 1 is upheld, but the discrepancy between the complete contract policy and the policy chosen by the government becomes smaller.

For an environment with an ISDS mechanism in place, the logic of Lemma 1 implies that, with $\theta_{2} \geq \bar{\theta}_{2}\left(s_{1}\right)$, a rise in $\alpha$ still lowers the regulation level in period two, conditional on $s_{1}$. The mechanism at work is the same as in a non-ISDS environment: For any given level of $s_{1}$, the marginal damage done by regulation weighs more heavily in the government's choice of $s_{2}$; for a formal proof see Appendix A.3. However, this is a partial effect that ignores the intertemporal dependency in regulation introduced by ISDS, which 
means that the second-period regulation is affected also through what a rise in $\alpha$ does to the level of regulation in the first period.

The first-order condition (13) tells us that the government's first-period calculation involves two parts. The first is the direct, concurrent effect of regulation on profits and regulation benefits, and the second is the intertemporal effect stemming from the government's anticipation of how period-one regulation affects its own behavior in period two, due to the ISDS mechanism. A rise in $\alpha$ adds weight to the concurrent damage of regulation, so the first part works towards a lower level of regulation also in period one, and according to Lemma 1 this reinforces the aforementioned anti-regulation effect in period two. As we have emphasized above, this second part represents a commitment consideration on the part of the government. This consideration is affected in two ways. First, since $\pi^{\prime \prime}<0$ and $v^{\prime \prime}<0$, a higher $s_{2}^{*}$, as caused by a higher $\alpha$, lowers the marginal welfare effect from any given intertemporal effect $\partial s_{2}^{*} / \partial s_{1}$, which works towards a higher period-one regulation, thus counteracting the effect operating through the non-strategic first-period consideration. And secondly, the commitment consideration is also affected through the magnitude of the intertemporal effect $\partial s_{2}^{*} / \partial s_{1}$. Appendix A.3 shows that the overall effect of the third channel is ambiguous. Consequently, and somewhat surprisingly, our conclusion is that a stronger domestic spillover effect from foreign investment may well lead to a more stringent period-one regulation. Indeed, in such a case we cannot rule out a more stringent second-period regulation as well. Due to the intertemporal effect in regulatory choice, a more stringent period-one regulation also increases the regulatory level in period two, and this effect may overcompensate the direct effect of a stronger spillover in period two.

A major concern often expressed is that an ISDS restricts access to a compensation mechanism to foreign firms, thus discriminating against domestic firms. However, domestic firms do not face the hold-up problem in the first place, because the domestic government will presumably take their profits into account, in addition to the spillover, when deciding on regulation. In the context of this model, the different treatment of foreign firms via ISDS is therefore not without justification. In the case where there are only domestic 
firms, they are equally exposed to the risk of an increase in the regulatory standard due to a large enough realization of $\theta_{2}$, but this would not constitute overregulation but simply reflect a change in circumstances. In the next section, we investigate national treatment in regulatory standards in the presence of domestic as well as foreign firms, treating this as a principle alternative to a standard ISDS mechanism open only to foreign firms.

Denying domestic firms access to ISDS may, however, cause a problem if firms can simply change their ownership status once they become unhappy with the specific regulation they are facing. This is an option that our model does not accommodate. For example, a domestic firm could move headquarters or do the investment via a foreign subsidiary to become a foreign firm with access to the compensation mechanism. Anticipating this reaction, the government would then take this into account in line with the above analysis, altering its regulatory behavior, although in fact there is no hold-up problem 34 In a similar vein, a foreign firm located in a country that has no investment agreement with the host country, or one without ISDS provision, could get access via a subsidiary in a country that has such an agreement ${ }^{35}$ In the next section we analyze whether a national treatment provision can do better than an ISDS provision in the context of our model, but it goes without saying that national treatment will definitely be immune against strategic ownership changes whereas ISDS is not.

\footnotetext{
${ }^{34}$ It does not help that a government dealing with a domestic firm will achieve the first best, because the firm will change its ownership upon facing tighter second-period regulation due to $\theta_{2}>\theta_{1}$. In doing so it can increase its expected profit due to an expected compensation after invoking ISDS.

${ }^{35} \mathrm{~A}$ famous case in point is Philip Morris, a US tobacco company, that has used its Hong Kong and Swiss subsidiaries to sue both the Australian and the Uruguayan government for its policy on cigarette packaging. Australia has an investment agreement with an ISDS provision with Hong Kong, and Uruguay with Switzerland, but both would not have anticipated this implication when signing it. In December 2015, the panel came out with a ruling in favor of the Australian government. It is interesting to note that the plaintiff has argued that the regulation on cigarette packaging at issue is equivalent to expropriation in exactly the sense envisaged by Article 9.8 of the TPP draft agreement; see also footnote 23
} 


\section{$4 \quad$ National treatment}

A national treatment provision should guarantee that all investors are subject to the same regulatory treatment irrespective of their nationality. Most agreements include both a national treatment provision and a most-favored-nation treatment provision. However, Articles 9.4 and 9.5 of the TPP draft (2016) restrict these provisions to " ...the establishment, acquisition, expansion, management, conduct, operation, and sale or other disposition of investments in its territory". Moreover, national treatment does not necessarily imply equal regulatory treatment until it will violate minimum standards of fair treatment. In particular, whether "treatment is accorded in 'like circumstances' " is said to depend on the "totality of the circumstances". Furthermore, Article 9.5 explicitly mentions that "the treatment ... does not encompass international dispute resolution procedures or mechanisms ...". Overall, the notion of a national treatment provision seems rather vague.

In this section, we consider a strict interpretation of a national treatment provision as an alternative to an ISDS provision. To lend this idea precise meaning, we assume that domestic and foreign firms are the same in all respects, except for their nationality. In particular, they have the same profit function, they create the same spillover $\alpha$ for the domestic economy, and they generate the same concern giving rise to regulation, as captured by $v(s)$. However, nationality plays out in the government's objective function where domestic firms' profits receive a full "weight" equal to $1+\alpha$, while foreign firms' profits matter only through their spillover $\alpha$. The government would therefore want to treat domestic and foreign investors differently, but is constrained through national treatment to a single regulatory standard $s$ applied to both types of firms.

\subsection{Domestic regulation under a national treatment provision}

It would certainly be naïve to expect from a national treatment restriction that the government sets common regulatory standards as if all firms were domestic when in fact some firms are foreign. When setting common standards, the effect on foreign firms is relevant 
only through the spillover effect. In order to keep the analysis clean from strategic interactions among firms, we assume a fixed number of domestic firms already active in the domestic economy. As before, the number of potential foreign entrants is normalized to one. Not all of them will enter, but the government knows the entry realization of period one when deciding on regulation in period two. Accordingly, let $\sigma^{*}$ denote the share of potential foreign investors that decide to enter at the beginning of period one; obviously, $0<\sigma^{*}<1$. Furthermore, let $\sigma>0$ denote the number of domestic firms relative to the number of potential foreign entrants. Note that the number of domestic firms may well be larger than the number of potential foreign investors, in which case $\sigma>1$. Importantly, both $\sigma$ and $\sigma^{*}$ are fixed after the first period.

The sequencing of decisions is as above, but now there is a further intertemporal link in that the level of foreign entry in period one is crucial for the government's regulation decision in period two. To see this, we first consider second-period regulation. Deprived of a discriminatory instrument, the domestic government will maximize period two domestic welfare

$$
\tilde{W}_{2}=\sigma(1+\alpha) \pi\left(s_{2}\right)+\sigma^{*} \alpha \pi\left(s_{2}\right)+\left(\sigma+\sigma^{*}\right) \theta_{2} v\left(s_{2}\right)
$$

with respect to $s_{2}$, observing that $\sigma^{*}$ foreign investors have entered in period one. Domestic welfare is now the sum of domestic profits, a weighted aggregate of domestic and foreign spillovers, and the benefits of regulating all firms. Since domestic (foreign) profits are (not) included, domestic firms are not themselves part of a hold-up problem, but national treatment exposes them to it as well. The strength of this effect depends on the ratio of $\sigma^{*}$ to $\sigma$. Maximization leads to a policy rule $s_{2}^{* *}\left(\theta_{2}, \sigma, \sigma^{*}\right)$ implicitly defined by the first-order condition 36

$$
\left[\left(\sigma(1+\alpha)+\sigma^{*} \alpha\right] \pi^{\prime}\left(s_{2}^{* *}\right)+\left(\sigma+\sigma^{*}\right) \theta_{2} v^{\prime}\left(s_{2}^{* *}\right)=0\right.
$$

Second-period regulation now also depends on the number of domestic firms $\sigma$ and on the foreign entry realization $\sigma^{*}$, in addition to the realization of $\theta_{2}$. We find:

\footnotetext{
${ }^{36}$ We use a double-star to denote optimal policies under national treatment (as opposed to single-starred notation for ISDS). Again, the second-order condition is satisfied under the assumptions made.
} 
Lemma 4. The second period regulation level is increasing in the number of foreign firms entering $\left(\sigma^{*}\right)$, and it is decreasing in the number of domestic firms $(\sigma)$.

Proof. See Appendix A.4.

The intuition is that an increase in the share of foreign firms having entered in period one increases the weight on the direct welfare effect of period-two regulation, one for one, whereas the weight on the negative profit effect of regulation increases less than proportionally, since $\alpha<1$. It thus aggravates the hold-up problem, leading to a higher period-two regulation. Conversely, a larger number of domestic firms works in the opposite direction because the negative effect on domestic firms' profits receives a weight $1+\alpha>1$.

Lemma 4 demonstrates a pro-regulation effect of a higher level of foreign entry: $\partial s_{2}^{* *}\left(\theta_{2}, \sigma, \sigma^{*}\right) / \partial \sigma^{*}>0$. Further below it will prove crucial how this effect varies with the number of domestic firms. Intuitively, a larger number of domestic firms should mitigate this pro-regulation effect, since it reduces the government's incentive to exploit the hold-up problem. It turns out, however, that this intuition is correct only if the initial ratio of domestic to foreign firms in the market surpasses a critical level. In order to shed some more light on this, suppose that $\pi_{t}\left(s_{t}\right)=\gamma-s_{t}$ and $v_{t}=\theta_{t} \ln \left(s_{t}\right)$ (see Appendix A.5 for details). If the share of domestic firms is large (small) such that

$$
\sigma>(<) \frac{\alpha}{1+\alpha} \sigma^{*}
$$

then $\partial^{2} s_{2}^{* *}\left(\theta_{2}, \sigma, \sigma^{*}\right) / \partial \sigma^{*} \partial \sigma$ is negative (positive). Note that $\partial^{2} s_{2}^{* *}\left(\theta_{2}, \sigma, \sigma^{*}\right) / \partial \sigma^{*} \partial \sigma<0$ implies that the incentive to increase second-order regulation as a response to an increase in the number of foreign entrants is reduced by an increase in domestic firms. Thus, if $\partial^{2} s_{2}^{* *}\left(\theta_{2}, \sigma, \sigma^{*}\right) / \partial \sigma^{*} \partial \sigma<0$, the marginal hold-up incentive loses strength with an increase in domestic firms.

As before, both the government and foreign investors will form rational expectations about the regulatory behavior in the second period, but now this includes the expectation about market entry. Rational expectations imply that the expectation of $\sigma^{*}$ is equal 
to $F(\bar{\phi})$ where $\bar{\phi}$ denotes the entry cost threshold. Furthermore, second-period regulation depends only on the number of entrants and not on their individual fixed cost realizations. Consequently, expected profits and expected regulation gains under national treatment, denoted by a tilde, are respectively given by

$$
\begin{aligned}
\tilde{\pi}_{2}(\sigma, \phi) & =\int_{\underline{\Theta}}^{\bar{\Theta}} \pi\left[s_{2}^{* *}(\theta, \sigma, F(\bar{\phi}))\right] \mathrm{d} G(\theta), \\
\tilde{R}_{2}(\sigma, \phi) & =\int_{\underline{\Theta}}^{\bar{\Theta}} \theta v\left[s_{2}^{* *}(\theta, \sigma, F(\bar{\phi}))\right] \mathrm{d} G(\theta) .
\end{aligned}
$$

Note that $\tilde{\pi}_{2}$ is the expected second-period profit not only of a foreign investor, but also of a domestic firm. As pointed out above, national treatment makes domestic firms "hostages" to the hold-up problem existing with foreign firms.

What about first-period regulation? The government no longer has an incentive to overregulate in the first period in order to have more discretion in the second period. Moreover, national treatment does not allow to specify different regulations for domestic firms and foreign investors in either period. Interestingly, this is the equilibrium outcome even if the government were allowed to discriminate in the first period. The domestic government maximizes domestic welfare generated by domestic firms (see first line below) and by foreign firms (see second line below),

$$
\begin{gathered}
\sigma\left[(1+\alpha)\left[\pi\left(s_{1}\right)+\tilde{\pi}_{2}(\sigma, \bar{\phi})\right]+\theta_{1} v\left(s_{1}\right)+\tilde{R}_{2}(\sigma, \bar{\phi})\right] \\
+\quad F(\bar{\phi})\left[\alpha\left[\pi\left(s_{1}\right)+\tilde{\pi}_{2}(\sigma, \bar{\phi})\right]+\theta_{1} v\left(s_{1}\right)+\tilde{R}_{2}(\sigma, \bar{\phi})-\Sigma\right]
\end{gathered}
$$

with respect to $s_{1}$ and $\Sigma$, subject to the participation constraint $\Sigma-\bar{\phi}+\left(\pi\left(s_{1}\right)+\tilde{\pi}_{2}(\sigma, \bar{\phi})\right) \geq$ 0. Again, this constraint will be binding, and we can rewrite this maximization problem in equivalent form, such that the domestic government maximizes

$$
\tilde{\Omega}=[\sigma+F(\bar{\phi})]\left[(1+\alpha)\left[\pi\left(s_{1}\right)+\theta_{1} v\left(s_{1}\right)\right]+\tilde{\Omega}_{2}(\sigma, \bar{\phi})\right]-F(\bar{\phi}) \bar{\phi}
$$

with respect to $s_{1}$ and $\bar{\phi}$, where we have used $\tilde{\Omega}_{2}(\sigma, \bar{\phi}):=(1+\alpha) \tilde{\pi}_{2}(\sigma, \bar{\phi})+\tilde{R}_{2}(\sigma, \bar{\phi})$ to 
denote the maximized second-period welfare per firm. The government now takes into account that entry of foreign firms will lead to second-period overregulation harming domestic firms. The first-order conditions are now given by

$$
\begin{aligned}
(1+\alpha) \pi^{\prime}\left(s_{1}^{* *}\right)+\theta_{1} v^{\prime}\left(s_{1}^{* *}\right) & =0, \\
{\left[\sigma+F\left(\bar{\phi}^{* *}\right)\right] \frac{\partial \tilde{\Omega}_{2}\left(\sigma, \bar{\phi}^{* *}\right)}{\partial \phi} } & \\
+f\left(\bar{\phi}^{* *}\right)\left[(1+\alpha)\left(\pi\left(s_{1}^{* *}\right)+\theta_{1} v\left(s_{1}^{* *}\right)+\tilde{\Omega}_{2}\left(\sigma, \bar{\phi}^{* *}\right)-\bar{\phi}^{* *}\right]-F\left(\bar{\phi}^{* *}\right)\right. & =0,
\end{aligned}
$$

where $s_{1}^{* *}$ and $\bar{\phi}^{* *}$ denote the optimal regulation level and the optimal entry level, respectively.

We observe from (18) that the first-period regulation will be first best if the government is not allowed to discriminate between domestic and foreign investors. But the same result would emerge if the government were allowed to do so in the first, but not in the second period. In fact, we see from (17) that the government has no incentive to treat domestic and foreign firms differently in the first period. As for domestic firms, it takes their profits directly into account; as for foreign firms, it does so by virtue of the participation constraint. Furthermore, a direct implication of this observation is that $\partial^{2} \tilde{\Omega} / \partial s_{1} \partial \phi=0$. Thus, we find:

Proposition 3. National treatment leads to the first-best regulation level in the first period, but the entry level is suboptimally low.

Proof. For the first part, see 18). For the second part, $(1+\alpha)\left(\pi\left(s_{1}^{* *}\right)+\tilde{\pi}_{2}\left(\sigma, \bar{\phi}^{* *}\right)\right)+$ $\theta_{1} v\left(s_{1}^{* *}\right)+\tilde{R}_{2}\left(\sigma, \bar{\phi}^{* *}\right)-\bar{\phi}^{* *}$ is less than its complete contract policy level (see Proposition 1 ), and $\partial \tilde{\Omega}_{2}\left(\sigma, \bar{\phi}^{* *}\right) / \partial \phi<0$ (see eq. A.20 in Appendix A.6.

Note that the entry distortion in the first period is twofold. First of all, second-period welfare is suboptimally low as in the case of ISDS. Since $s_{2}^{* *}$ is inefficiently high, entry is too low, as in the case without ISDS, but it is not clear whether it is higher or lower than its counterpart under ISDS. As in the case without investor protection, the anticipation of overregulation in the second period implies a suboptimally low level of entry despite 
the entry subsidy, because overregulation reduces the welfare contribution of the marginal entrant. The second effect, originating from $\partial \tilde{\Omega}_{2}\left(\sigma, \bar{\phi}^{* *}\right) / \partial \phi<0$, is an additional distortion imposed by a national treatment provision that has no ISDS-counterpart: The government correctly anticipates that foreign entry will increase the second-period regulation standard harming domestic firms as well.

\subsection{National treatment versus ISDS}

How does a national treatment provision compare with ISDS in terms of global welfare? While this question may seem hard to answer without specifying functional forms, our approach opens up an avenue for a general result. To see this, we first note that both, national treatment and ISDS, involve their own, specific distortions: under ISDS (allowing for discrimination), the welfare generated by each domestic firm is at its maximum level, but below maximum for foreign entrants. Under a national treatment provision, welfare generated by each firm, domestic as well as foreign, is smaller than its maximum, provided that $\sigma^{*}>0$. Moreover, this latter distortion is entirely due to overregulation in the second period, since the first-period regulation is first best. And importantly, secondperiod overregulation is strictly decreasing in the number of domestic firms $\sigma$. If $\sigma$ becomes very large, then $s_{2}^{* *}$ will be close to first best. All of this seems to suggest that there should be a critical number of domestic firms above which national treatment welfare-dominates ISDS.

This is, indeed, the main idea underlying our welfare result below, but we have to include the entry decision as well. Foreign entry is suboptimally low under both, national treatment and ISDS. That foreign entry increases with the number of domestic firms under national treatment, however, is not clear, as the first-order condition (19) identifies several (opposing) effects. As for the second line of (19), an increase in $\sigma$ increases the welfare cost from exposing domestic firms to the hold-up problem, and the domestic government will therefore want to reduce foreign entry for any given level of regulation $s_{2}$. At the same time, a higher $\sigma$ will prompt the government to reduce $s_{2}$ (Lemma 4), which in turn reduces the welfare cost for each domestic firm. Furthermore, as shown by the first line of 
(19), foreign entry will negatively affect second-period welfare. However, we do not know whether an increase in $\sigma$ will amplify or reduce this effect. ${ }^{37}$ We find:

Proposition 4. If $\sigma>F\left(\bar{\phi}^{* *}\right)$ and $\partial^{2} s_{2}^{* *}\left(\theta_{2}, \sigma^{*}, \sigma\right) / \partial \sigma^{*} \partial \sigma<0$, domestic and global welfare increases with $\sigma$. If $\sigma$ is sufficiently large, a national treatment provision welfaredominates ISDS.

Proof. See Appendix A.6.

Proposition 4 shows that welfare increases with $\sigma$ if $\sigma$ is sufficiently large to begin with, due to $\partial s_{2}^{* *}\left(\theta_{2}, \sigma^{*}, \sigma\right) / \partial \sigma<0$, and if an increase in $\sigma$ reduces the marginal hold-up incentive, i.e., if $\partial^{2} s_{2}^{* *}\left(\theta_{2}, \sigma^{*}, \sigma\right) / \partial \sigma^{*} \partial \sigma<0$ holds. Note that the conditions developed here are all sufficient, not necessary. Hence, it may well be that a national treatment provision does better even if one of these conditions is violated. Proposition 4 shows that a national treatment provision definitely works better, if the number of domestic firms is large enough and if the pro-regulation effect of foreign entry is reduced through an increase in the number of domestic firms. In this case, a sufficiently large number of domestic firms makes both the entry distortion in the first period and the hold-up distortion in the second period sufficiently small for the national treatment provision to deliver a higher level of global welfare than an ISDS provision. Note that $\sigma>F\left(\bar{\phi}^{* *}\right)$ fulfills condition (16) and implies $\partial^{2} s_{2}^{* *}\left(\theta_{2}, \sigma^{*}, \sigma\right) / \partial \sigma^{*} \partial \sigma<0$. Thus, for the specification leading to condition (16), a sufficiently large share of domestic firms will make a national treatment provision welfaredominant. Appendix A.6 shows that national treatment converges to the optimal levels with an increase in the number of domestic firms relative to potential foreign entrants, including the complete contract policy entry level.

At the same time, we want to make very clear that Proposition 4 should not be misread such that national treatment is always welfare-dominating if domestic firms outnumber potential foreign entrants. It could well be that only domestic firms are active, even if there are many, simply because the domestic government wants to keep all foreign investors out

\footnotetext{
${ }^{37}$ Appendix A.6 shows that $\partial^{2} \tilde{\Omega}_{2}\left(\sigma, \bar{\phi}^{* *} / \partial \phi \partial \sigma\right.$ depends on the sign of $\partial^{2} s_{2}^{* *} / \partial \sigma^{*} \partial \sigma$.
} 
of its country. This is the case if a single foreign entrant would inflict more damage to all domestic firms due to the potential overregulation in the second period than it adds to domestic welfare in terms of spillovers to the local economy. Thus, Proposition 4 shows that it is not just a sufficient number of domestic firms, but also the response of secondperiod regulation to entry that determines whether national treatment is a preferred commitment device.

We cannot, however, expect that every industry has both domestic and foreign firms. In some cases, countries try to attract foreign direct investment precisely because a domestic industry does not exist, and multinational firms are needed to produce goods and/or provide services that domestic firms cannot offer. In these cases, national treatment has no bite. The same is true if $s$ is a treatment that applies to foreign firms only, but not to domestic firms. Examples are tax holidays for foreign firms (or any other forms of concessions to foreign firms only) ${ }^{38}$ any service provided by the government that is valuable only to foreign firms and regulation that is based on individualized measures. We thus conclude that an ISDS provision with a sufficiently low value of $\rho$ welfare-dominates national treatment if no domestic firm is affected by regulation or if the regulatory design relies on individualized measures. Consequently, the potential success of national treatment will also depend on the regulatory design. A firm-specific design, like an environmental policy using individualized command and control measures, makes any national treatment provision useless.

In our model, domestic and foreign firms are completely symmetric, so any violation of strict national treatment rules is easily established. This is not the case if domestic and foreign firms differ structurally, for example with respect to their productivity. This may give the national government some leeway in undermining national treatment rules to protect their domestic industry, and thus national treatment may require a dispute settlement provision as well. This is true in particular if national treatment provisions are firm- or industry-specific as a micromanagement of these provisions will give a host

\footnotetext{
${ }^{38}$ For tax holidays, see Bond and Samuelson $(1986,1989)$ and Doyle and van Wjinbergen (1994).
} 
country some discretion to protect domestic firms. For example, regulatory measures could be such that high productivity firms are affected stronger by regulation if foreign entrants are more productive on average. Thus, an additional advantage of a general regulatory design in this context is that it will imply less discretion for host countries and thus also fewer dispute settlement cases.

\section{Concluding remarks}

International investment agreements include provisions that aim at protecting foreign investors against opportunistic behavior of host country governments. Using a simple twoperiod model where foreign investors are subject to domestic regulation, we have shown that both ISDS and national treatment provisions have the potential to mitigate this holdup problem. Both, however, also cause additional distortions. With ISDS, the government will either underregulate in the first period in order to commit to investor-friendly policies in the future, or it will overregulate to buy more discretion in the future. With national treatment, the government has less incentives to promote foreign entry. Provided that the entry distortion becomes smaller as the number of domestic firms increases, a sufficiently large number of domestic firms makes a national treatment provision a better way to deal with the hold-up problem than an ISDS provision.

A general policy implication is that a regulatory framework should be as general as possible, meaning that it should cover several industries or even all economic activities in the same way. National treatment provisions have no bite if regulations are firm-specific, but can deal with the hold-up problem if regulatory treatment is defined in a general way, provided that the number of domestic activities subject to the same regulation is not too small. For example, if a country faces a need for environmental regulation, a tax on all polluting activities may guarantee the large number of affected domestic firms needed for a successful national treatment provision, but industry- or even firm-specific standards do not. If governments succeed in adjusting the regulatory framework in this sense, they also avoid all the additional problems that an ISDS mechanism may create that our model 
could not accommodate.

ISDS provisions may help if the regulatory design affects foreign firms only and cannot be extended to include a sufficiently large number of domestic firms. However, it seems that two problems will persist. First, ISDS provisions are far from being specific and seem to be less developed than dispute settlement provisions in international trade. This discretion may give multinational firms an advantage in winning cases, and it is thus not clear whether ISDS provisions will primarily lead to rent seeking, or whether they will have a positive effect on investment. Second, ISDS provisions may trigger strategic ownership changes as multinational firms can get access to ISDS provisions even in their home countries through foreign subsidiaries. In any case, it seems that national treatment provisions as an alternative have not yet been brought to their full potential. Therefore, a neglected issue in negotiations on investor protection is that countries could also agree on more general regulatory frameworks as far as possible.

\section{Appendix}

\section{A.1 Proof of Proposition 1}

We use $s_{t}^{\mathrm{cc}}$ and $\bar{\phi}^{\mathrm{cc}}$, respectively, to denote the complete contract levels of regulation and the entry threshold. First-best levels chosen by a social planner are denoted by $s_{t}^{\text {opt }}$ and $\bar{\phi}^{\mathrm{opt}}$. The complete contract policy is defined through a welfare function like (2), but with $\hat{\pi}_{2}$ and $\hat{R}_{2}$ replaced by $\pi_{2}^{\text {opt }}$ and $R_{2}^{\text {opt }}$ corresponding to a period two regulation standard $s_{2}^{\text {opt }}\left(\theta_{2}\right)$ implicitly determined by the condition $(1+\alpha) \pi^{\prime}\left(s_{2}^{\mathrm{opt}}\right)+\theta_{2} v^{\prime}\left(s_{2}^{\mathrm{opt}}\right)=0$ that maximizes global second-period welfare. Under the assumptions made, this implies that the government overregulates in period two: $s_{2}^{*}\left(\theta_{2}\right)>s_{2}^{\mathrm{opt}}\left(\theta_{2}\right)$ and $(1+\alpha) \pi_{2}^{\mathrm{opt}}+R_{2}^{\mathrm{opt}}>$ $(1+\alpha) \hat{\pi}_{2}+\hat{R}_{2}$, where $\pi_{2}^{\text {opt }}$ and $R_{2}^{\text {opt }}$ are defined by complete analogy to $\hat{\pi}_{2}$ and $\hat{R}_{2}$. Since welfare is additive over the two periods, the period one regulation is first best: $s_{1}^{*}=s_{1}^{\text {opt }}$ (see the first line in (3)). The complete contract entry threshold $\bar{\phi}^{\text {cc }}$ is implicitly determined by

$$
f\left(\bar{\phi}^{\mathrm{cc}}\right)\left[(1+\alpha)\left[\pi\left(s_{1}^{*}\right)+\pi_{2}^{\mathrm{opt}}\right]+\theta_{1} v\left(s_{1}^{*}\right)+R_{2}^{\mathrm{opt}}-\bar{\phi}^{\mathrm{cc}}\right]-F\left(\bar{\phi}^{\mathrm{cc}}\right)=0 .
$$


To compare this with the first-order condition for the government policy, we use $\Omega=$ $(1+\alpha)\left[\pi\left(s_{1}^{*}\right)+\pi_{2}\right]+\theta_{1} v\left(s_{1}^{*}\right)+R_{2}$ and differentiate the second line in eq. (3) to obtain

$$
\frac{\mathrm{d} \phi}{\mathrm{d} \Omega}=\frac{f\left(\phi^{*}\right)}{f^{\prime}\left(\phi^{*}\right)\left(\Omega^{*}-\phi^{*}\right)-2 f\left(\phi^{*}\right)}>0
$$

with the inequality following from the second-order condition. Thus, $\Omega^{\text {cc }}>\Omega^{*}$ implies $\bar{\phi}^{\mathrm{cc}}>\bar{\phi}^{*}$.

It is obvious that a social planner will choose efficient rules of regulation for both periods, $s_{2}^{\text {opt }}\left(\theta_{2}\right)$ and $s_{1}^{\mathrm{opt}}\left(\theta_{1}\right)$. As regards period one, the planner solves

$$
\max _{s_{1}, \bar{\phi}} \int_{\underline{\phi}}^{\bar{\phi}}\left\{\left[(1+\alpha) \pi\left(s_{1}\right)+\theta_{1} v\left(s_{1}\right)\right]+(1+\alpha) \pi_{2}^{\text {opt }}+R_{2}^{\text {opt }}-\phi\right\} \mathrm{d} F(\phi)
$$

The first-order condition for $s_{1}$ is the same as for the complete contract policy, which is in turn equal to $s_{1}^{*}$. In the above expression, we therefore have $\pi\left(s_{1}^{*}\right)$ and $v\left(s_{1}^{*}\right)$. The first-order condition for the first-best entry level is given by

$$
\bar{\phi}^{\mathrm{opt}}=(1+\alpha)\left[\pi\left(s_{1}^{*}\right)+\pi_{2}^{\mathrm{opt}}\right]+\theta_{1} v\left(s_{1}^{*}\right)+R_{2}^{\mathrm{opt}}
$$

while using the first-order condition A.1 yields

$$
\bar{\phi}^{\mathrm{opt}}=(1+\alpha)\left(\pi\left(s_{1}^{*}\right)+\pi_{2}^{\mathrm{opt}}\right)+\theta_{1} v\left(s_{1}^{*}\right)+R_{2}^{\mathrm{opt}}-\frac{F\left(\phi^{\mathrm{opt}}\right)}{f\left(\phi^{\mathrm{opt}}\right)}=\bar{\phi}^{\mathrm{cc}}-\frac{F\left(\phi^{\mathrm{opt}}\right)}{f\left(\phi^{\mathrm{opt}}\right)}<\bar{\phi}^{\mathrm{cc}}
$$

The subsidy level $\Sigma^{\mathrm{opt}}$ corresponding to $\phi^{\mathrm{opt}}$ follows from $\phi^{\mathrm{opt}}=\pi\left(s_{1}\right)+\hat{\pi}_{2}-\Sigma$. Inserting first best values we have

$$
\Sigma^{\mathrm{opt}}=\alpha\left[\pi\left(s_{1}^{*}\right)+\pi_{2}^{\mathrm{opt}}\right]+\theta_{1} v\left(s_{1}^{*}\right)+R_{2}^{\mathrm{opt}} .
$$

The optimal level of the subsidy corrects for the welfare effects of entry ignored by the private investor.

\section{A.2 ISDS: Proof of Proposition 2 and of Lemma 2}

We use $\psi_{2}\left(s_{2}^{*}, \theta_{2}, s_{1}, \rho\right)=0$ as a shorthand for the first-order condition (11) determining $s_{2}^{*}$, the short-hand $\psi_{1}\left(s_{1}^{*}, \rho\right)=0$ is used for the first-order condition (13) determining $s_{1}^{*}$, and $\psi_{3}\left(\bar{\phi}^{*}, s_{1}^{*}, \rho\right)$ serves as a short-hand for condition (14) determining $\bar{\phi}^{*}$. 
The second-order conditions then imply $\partial \psi_{1} / \partial s_{1}, \partial \psi_{2} / \partial s_{2}, \partial \psi_{3} / \partial \bar{\phi}<0$. We need to derive $\mathrm{d} s_{1}^{*} / \mathrm{d} \rho=-\left(\partial \psi_{1} / \partial \rho\right) /\left(\partial \psi_{1} / \partial s_{1}\right), \mathrm{d} s_{2}^{*} / \mathrm{d} \rho=-\left(\partial \psi_{2} / \partial \rho\right) /\left(\partial \psi_{2} / \partial s_{2}\right)$ and $\mathrm{d} \bar{\phi}^{*} / \mathrm{d} \rho=$ $-\left(\partial \psi_{3} / \partial \rho\right) /\left(\partial \psi_{3} / \partial \bar{\phi}\right)$.

We first collect different partial derivatives incorporated in in these effects, starting with $t\left(s_{1}, s_{2}^{*}, \theta_{2}\right)$. We find:

$$
\begin{aligned}
\frac{\partial t\left(s_{1}, s_{2}^{*}, \theta_{2}\right)}{\partial s_{1}}= & \underbrace{\frac{\partial \mathbb{E}\left[\mu(\cdot) \mid \theta_{2}\right]}{\partial s_{1}}}_{\leq 0} \pi^{\prime}\left(s_{2}^{*}\right)-\underbrace{\frac{\partial \mathbb{E}\left[\mu(\cdot) \mid \theta_{2}\right]}{\partial s_{2}}}_{\geq 0} \pi^{\prime}\left(s_{1}\right) \\
& -\underbrace{\frac{\partial^{2} \mathbb{E}\left[\mu(\cdot) \mid \theta_{2}\right]}{\partial s_{2} \partial s_{1}}}_{\leq 0}\left[\pi\left(s_{1}\right)-\pi\left(s_{2}^{*}\right)\right] \geq 0,
\end{aligned}
$$

where the signs follows from the assumptions on $\mu$ : $\partial \mu / \partial s_{1} \leq 0, \partial \mu / \partial s_{2} \geq 0$ (already made above) and the additional plausible assumption that $\partial^{2} \mu / \partial s_{2} \partial s_{1} \leq 0$, meaning the the marginal effect of $s_{2}$ on the likelihood of a compensation ruling by the panel is decreasing in $s_{1}$. We therefore have $\partial t\left(s_{1}, s_{2}^{*}, \theta_{2}\right) / \partial s_{1} \geq 0$. For the change with $s_{2}$, we find:

$$
\begin{aligned}
\frac{\partial t\left(s_{1}, s_{2}^{*}, \theta_{2}\right)}{\partial s_{2}}= & 2 \underbrace{\frac{\partial \mathbb{E}\left[\mu(\cdot) \mid \theta_{2}\right]}{\partial s_{2}}}_{\geq 0} \pi^{\prime}\left(s_{2}^{*}\right)+\mathbb{E}\left[\mu(\cdot) \mid \theta_{2}\right] \pi^{\prime \prime}\left(s_{2}^{*}\right) \\
& -\underbrace{\frac{\partial^{2} \mathbb{E}\left[\mu(\cdot) \mid \theta_{2}\right]}{\partial s_{2}^{2}}}_{\geq 0}\left[\pi\left(s_{1}\right)-\pi\left(s_{2}^{*}\right)\right] \leq 0,
\end{aligned}
$$

where the first inequality again follows from the assumptions already made above, and the second inequality follows from the plausible assumption $\partial^{2} \mu / \partial s_{2}^{2} \geq 0$, meaning that the marginal effect of $s_{2}$ on the likelihood of a compensation ruling by the panel is nondecreasing in $s_{2}$. Since $\pi\left(s_{1}\right)-\pi\left(s_{2}^{*}\right)>0$ if $\theta_{2} \geq \bar{\theta}_{2}\left(s_{1}\right)$, we have $\partial t\left(s_{1}, s_{2}^{*}, \theta_{2}\right) / \partial s_{2} \leq 0$.

Next, we know from the proof of Lemma 1 that for $\theta_{2}>\bar{\theta}_{2}\left(s_{1}\right)$, we have

$$
\frac{\partial s_{2}^{*}}{\partial s_{1}}=-\frac{\partial \psi_{2} / \partial s_{1}}{\partial \psi_{2} / \partial s_{2}} \geq 0 \text { and } \frac{\partial s_{2}^{*}}{\partial \rho}=-\frac{\partial \psi_{2} / \partial \rho}{\partial \psi_{2} / \partial s_{2}}<0
$$

where the inequality signs follow from

$$
\frac{\partial \psi_{2}}{\partial s_{1}}=\rho \frac{\partial t\left(s_{1}, s_{2}^{*}, \theta_{2}\right)}{\partial s_{1}} \geq 0 \text { and } \frac{\partial \psi_{2}}{\partial \rho}=t\left(s_{1}, s_{2}^{*}, \theta_{2}\right)<0
$$


For $\theta_{2}<\bar{\theta}_{2}\left(s_{1}\right)$, we have $\partial \psi_{2} / \partial s_{1}=0$ as well as $\partial \psi_{2} / \partial \rho=0$, so the partial derivatives for $s_{2}^{*}$ in A.5 are both zero.

We shall also need the cross derivative

$$
\frac{\partial^{2} s_{2}^{*}}{\partial s_{1} \partial \rho}=-\left[-\frac{\frac{\partial \psi_{2}}{\partial s_{1}} \frac{\partial^{2} \psi_{2}}{\partial s_{2} \partial \rho}}{\left(\partial \psi_{2} / \partial s_{2}\right)^{2}}+\frac{\frac{\partial^{2} \psi_{2}}{\partial s_{1} \partial \rho}}{\partial \psi_{2} / \partial s_{2}}\right]=\frac{\frac{\partial \psi_{2}}{\partial s_{1}} \frac{\partial^{2} \psi_{2}}{\partial s_{2} \partial \rho}-\frac{\partial^{2} \psi_{2}}{\partial s_{1} \partial \rho} \frac{\partial \psi_{2}}{\partial s_{2}}}{\left(\partial \psi_{2} / \partial s_{2}\right)^{2}}
$$

It is easy to see that

$$
\partial^{2} \psi_{2} / \partial s_{2} \partial \rho=\partial t\left(s_{1}, s_{2}^{*}, \theta_{2}\right) / \partial s_{2} \leq 0 \text { and } \partial^{2} \psi_{2} / \partial s_{1} \partial \rho=\partial t\left(s_{1}, s_{2}^{*}, \theta_{2}\right) / \partial s_{1} \geq 0,
$$

hence we may use A.6 to rewrite A.7 as

$$
\begin{aligned}
\frac{\partial^{2} s_{2}^{*}}{\partial s_{1} \partial \rho} & =-\frac{\partial t\left(s_{1}, s_{2}^{*}, \theta_{2}\right) / \partial s_{1}}{\left(\partial \psi_{2} / \partial s_{2}\right)^{2}}\left[\frac{\partial \psi_{2}}{\partial s_{2}}-\rho \frac{\partial t\left(s_{1}, s_{2}^{*}, \theta_{2}\right)}{\partial s_{2}}\right] \\
& =-\frac{\partial t\left(s_{1}, s_{2}^{*}, \theta_{2}\right) / \partial s_{1}}{\left(\partial \psi_{2} / \partial s_{2}\right)^{2}}\left[\alpha \pi^{\prime \prime}\left(s_{2}^{*}\right)+\theta_{2} v^{\prime \prime}\left(s_{2}^{*}\right)\right]>0
\end{aligned}
$$

where the second equality follows from $\partial \psi_{2} / \partial s_{2}=\alpha \pi^{\prime \prime}\left(s_{2}^{*}\right)+\theta_{2} v^{\prime \prime}\left(s_{2}^{*}\right)+\rho \partial t\left(s_{1}, s_{2}^{*}, \theta_{2}\right) / \partial s_{2}$, and the inequality follows from $\pi^{\prime \prime}(\cdot)<0, v^{\prime \prime}(\cdot)<0$ and $\partial t\left(s_{1}, s_{2}^{*}, \theta_{2}\right) / \partial s_{1} \geq 0$.

We can now turn to the comparative statics of $s_{1}^{*}$. From the first-order condition $\psi_{1}(\cdot)=0$, the sign of $\mathrm{d} s_{1}^{*} / \mathrm{d} \rho=-\left(\partial \psi_{1} / \partial \rho\right) /\left(\partial \psi_{1} / \partial s_{1}\right)$, depends on the sign of $\partial \psi_{1} / \partial \rho=(1+\alpha) \partial^{2} \hat{\pi}_{2} / \partial s_{1} \partial \rho+\partial^{2} \hat{R}_{2} / \partial s_{1} \partial \rho$, since due to the second-order condition we have $\partial \psi_{1} / \partial s_{1}<0$. We first note that

$$
\frac{\partial \hat{\pi}_{2}\left(s_{1}^{*}, \rho\right)}{\partial s_{1}}=\int_{\underline{\Theta}}^{\bar{\Theta}} \pi^{\prime}\left(s_{2}^{*}\right) \frac{\partial s_{2}^{*}}{\partial s_{1}} \mathrm{~d} G(\theta) \quad \text { and } \quad \frac{\partial \hat{R}_{2}\left(s_{1}^{*}, \rho\right)}{\partial s_{1}} \int_{\underline{\Theta}}^{\bar{\Theta}} \theta v^{\prime}\left(s_{2}^{*}\right) \frac{\partial s_{2}^{*}}{\partial s_{1}} \mathrm{~d} G(\theta)
$$

where both $s_{2}^{*}$ as well as $\partial s_{2}^{*} / \partial s_{1}$ as derived above depend on $\theta_{2}$. From (11), we find:

$$
\begin{aligned}
\frac{\partial \psi_{1}}{\partial \rho}= & \int_{\bar{\theta}_{2}\left(s_{1}^{*}\right)}^{\bar{\Theta}}\left[(1+\alpha) \pi^{\prime \prime}\left(s_{2}^{*}\right)+\theta v^{\prime \prime}\left(s_{2}^{*}\right)\right] \frac{\partial s_{2}^{*}}{\partial \rho} \frac{\partial s_{2}^{*}}{\partial s_{1}} \mathrm{~d} G(\theta) \\
& +\int_{\bar{\theta}_{2}\left(s_{1}^{*}\right)}^{\bar{\Theta}}\left[(1+\alpha) \pi^{\prime}\left(s_{2}^{*}\right)+\theta v^{\prime}\left(s_{2}^{*}\right)\right] \frac{\partial^{2} s_{2}^{*}}{\partial s_{1} \partial \rho} \mathrm{d} G(\theta)
\end{aligned}
$$

Using eqs. A.5, A.6 as well as A.8, and rewriting the first-order condition (11) as 
$(1+\alpha) \pi^{\prime}\left(s_{2}^{*}\right)+\theta v^{\prime}\left(s_{2}^{*}\right)=\pi^{\prime}\left(s_{2}^{*}\right)-\rho t\left(s_{1}^{*}, s_{2}^{*}, \theta_{2}\right)$, we obtain

$$
\begin{aligned}
& \frac{\partial \psi_{1}}{\partial \rho}=\int_{\bar{\theta}_{2}\left(s_{1}^{*}\right)}^{\bar{\Theta}} \underbrace{\frac{\partial t\left(s_{1}^{*}, s_{2}^{*}, \theta\right) / \partial s_{1}}{\left(\partial \psi_{2} / \partial s_{2}\right)^{2}}}_{\geq 0} \times \\
& {[\underbrace{\rho t\left(s_{1}^{*}, s_{2}^{*}, \theta\right) \pi^{\prime \prime}\left(s_{2}^{*}\right)}_{>0}+\underbrace{\left[\alpha \pi^{\prime \prime}\left(s_{2}^{*}\right)+\theta v^{\prime \prime}\left(s_{2}^{*}\right)\right]}_{<0}\left[2 \rho t\left(s_{1}^{*}, s_{2}^{*}, \theta\right)-\pi^{\prime}\left(s_{2}^{*}\right)\right]] \mathrm{d} G(\theta) \text {. }}
\end{aligned}
$$

From A.10, we observe that in general $\mathrm{d} s_{1}^{*} / \mathrm{d} \rho$ is ambiguous in sign. However, for $\rho=0$, we find that the bracketed term above is negative for any value of $\theta$, whence the partial derivative is negative and $\mathrm{d} s_{1}^{*} /\left.\mathrm{d} \rho\right|_{\rho=0}<0$. By continuity, this sign holds true also in the neighborhood of $\rho=0$, which proves what Proposition 2 states on $s_{1}^{*}$.

Setting $\partial \psi_{1} / \partial \rho$ in A.10 equal to zero gives the first-order condition for the minimum of $s_{1}^{*}$ with respect to $\rho$ :

$$
\rho=\frac{\int_{\bar{\theta}_{2}\left(s_{1}\right)}^{\overline{\bar{N}}} \frac{\partial t\left(s_{1}^{*}, s_{2}^{*}, \theta\right) / \partial s_{1}}{\left(\partial \psi_{2} / \partial s_{2}\right)^{2}} \pi^{\prime}\left(s_{2}^{*}\right)\left[\alpha \pi^{\prime \prime}\left(s_{2}^{*}\right)+\theta v^{\prime \prime}\left(s_{2}^{*}\right)\right] \mathrm{d} G(\theta)}{\int_{\bar{\theta}_{2}\left(s_{1}\right)}^{\bar{\Theta}} \frac{\partial t\left(s_{1}^{*}, s_{2}^{*}, \theta\right) / \partial s_{1}}{\left(\partial \psi_{2} / \partial s_{2}\right)^{2}} t\left(s_{1}^{*}, s_{2}^{*}, \theta\right)\left[\pi^{\prime \prime}\left(s_{2}^{*}\right)+2\left[\alpha \pi^{\prime \prime}\left(s_{2}^{*}\right)+\theta v^{\prime \prime}\left(s_{2}^{*}\right)\right]\right] \mathrm{d} G(\theta)} .
$$

Remember that in this expression $s_{2}^{*}=s_{2}^{*}\left(s_{1}^{*}, \theta, \rho\right)$. Suppose there is a solution to this condition, determining a value $\tilde{\rho}>0$ that locally minimizes the first period regulation $s_{1}^{*}$ under an ISDS. If $s_{1}^{*}\left(\theta_{1}, \rho\right)$ is convex in $\rho$, then $s_{1}^{*}\left(\theta_{1}, \rho\right)$ has a global minimum at $\rho=\tilde{\rho}$. Moreover, there will be a value $\check{\rho}>\tilde{\rho}$ where $s_{1}^{*}\left(\theta_{1}, \check{\rho}\right)$ is larger than the first period regulation without ISDS, which proves Lemma 2. Note that $\pi^{\prime}\left(s_{2}^{*}\right) / t\left(s_{1}^{*}, s_{2}^{*}, \theta_{2}\right)>\tilde{\rho}>0$.

The comparative statics of $s_{1}^{*}$ imply for the comparative statics of $s_{2}^{*}$ that

$$
\frac{\mathrm{d} s_{2}^{*}}{\mathrm{~d} \rho}=\frac{\partial s_{2}^{*}}{\partial s_{1}} \frac{\mathrm{d} s_{1}^{*}}{\mathrm{~d} \rho}+\frac{\partial s_{2}^{*}}{\partial \rho}
$$

which is negative if $\mathrm{d} s_{1}^{*} / \mathrm{d} \rho<0$. This proves the first part of Proposition 2 for sufficiently low values of $\rho$ an ISDS mechanism leads to lower regulation in both periods.

Next we turn to the entry level and domestic welfare. We may rewrite the first-order condition for $\bar{\phi}^{*}$ in 14 as

$$
\psi_{3}\left(\bar{\phi}^{*}, s_{1}^{*}, \rho\right)=f\left(\bar{\phi}^{*}\right) \Lambda-F\left(\bar{\phi}^{*}\right)
$$




$$
\text { with } \frac{\partial \psi_{3}}{\partial \rho}=f\left(\bar{\phi}^{*}\right) \frac{\partial \Lambda}{\partial \rho}
$$

where $\Lambda$ is the bracketed term in (14). From this definition of $\Lambda$, we have

$$
\begin{aligned}
\frac{\partial \Lambda}{\partial \rho} & =\int_{\bar{\theta}_{2}\left(s_{1}\right)}^{\bar{\Theta}} \frac{\partial \Lambda}{\partial s_{2}^{*}} \frac{\partial s_{2}^{*}}{\partial \rho} \mathrm{d} G(\theta)=\int_{\bar{\theta}_{2}\left(s_{1}\right)}^{\bar{\Theta}}\left[(1+\alpha) \pi^{\prime}\left(s_{2}^{*}\right)+\theta v^{\prime}\left(s_{2}^{*}\right)\right] \frac{\partial s_{2}^{*}}{\partial \rho} \mathrm{d} G(\theta) \\
& =\int_{\bar{\theta}_{2}\left(s_{1}\right)}^{\bar{\Theta}}\left[\pi^{\prime}\left(s_{2}^{*}\right)-\rho t\left(s_{1}, s_{2}^{*}, \theta\right)\right] \frac{\partial s_{2}^{*}}{\partial \rho} \mathrm{d} G(\theta)
\end{aligned}
$$

where the last line follows from the first-order condition for $s_{2}^{*}$ in (11). We recognize that for $\rho=0$ the effect $\partial \Lambda / \partial \rho$ is positive; otherwise it is ambiguous. In general, then, ambiguity also rules for the comparative static effect of $\rho$ on the entry threshold $\bar{\phi}^{*}$ :

$$
\frac{\mathrm{d} \bar{\phi}^{*}}{\mathrm{~d} \rho}=-\frac{\partial \psi_{3} / \partial \rho}{\partial \psi_{3} / \partial \bar{\phi}}=-\frac{1}{\partial \psi_{3} / \partial \bar{\phi}} f\left(\bar{\phi}^{*}\right) \frac{\partial \Lambda}{\partial \rho} .
$$

But in the neighborhood of $\rho=0$, since $\partial \Lambda / \partial \rho<0$, we have a positive effect, which proves the second part of Proposition 2, an ISDS mechanism leads to more FDI entry. Finally, applying the Envelope Theorem to domestic welfare $\Omega=F\left(\bar{\phi}^{*}\right) \Lambda$, we obtain

$$
\frac{\mathrm{d} \Omega}{\mathrm{d} \rho}=F\left(\bar{\phi}^{*}\right) \frac{\partial \Lambda}{\partial \rho}
$$

It follows from (A.14) that the sign of $\partial \Lambda / \partial \rho$ is generally equal to the sign of $\mathrm{d} \bar{\phi}^{*} / \mathrm{d} \rho$. For $\rho$ sufficiently small in magnitude, we have $\partial \Lambda / \partial \rho>0$. For sufficiently large values of $\rho$ to start with, the marginal effects of $\rho$ on $s_{1}^{*}$ and $\Lambda$ may be of opposite sign, in which case the welfare effect is driven by the change in $\Lambda$ and, thus, the change in the entry threshold $\bar{\phi}^{*}$, and not by the effect on regulatory levels $s_{1}^{*}$ and $s_{2}^{*}$. For a discrete comparison between ISDS-ridden welfare and laissez-faire welfare (no ISDS), ISDS-ridden welfare is larger, provided that welfare is monotonic in $\rho$ : An ISDS mechanism improves domestic welfare, provided that it increases the entry threshold $\bar{\phi}^{*}$. The increase in global welfare follows from the result that the entry threshold $\bar{\phi}^{*}$ is too low from a global perspective and that the global welfare function is concave; see Proposition 1. As entry increases, all foreign investors, and not only the marginal investor, are better off. 


\section{A.3 Spillover parameter and regulation with ISDS}

We first consider the second-period regulation $s_{2}^{*}$, conditional on $s_{1}$ : Writing the first-order condition (11) as $\psi_{2}\left(\alpha, s_{2}^{*}, \theta_{2}, s_{1}, \rho\right)=0$, holding $s_{1}$ constant, we have $\partial \psi_{2} / \partial \alpha=\pi^{\prime}\left(s_{2}^{*}\right)$, whence $\partial s_{2}^{*} / \partial \alpha=-\pi^{\prime}\left(s_{2}^{*}\right) /\left(\partial \psi_{2} / \partial s_{2}\right)<0$, where the inequality follows from the secondorder condition on $s_{2}^{*}$. Moreover, due to A.7) and (A.8), we may state that

$$
\frac{\partial^{2} s_{2}^{*}}{\partial s_{1} \partial \alpha}=\rho \frac{\partial t\left(s_{1}, s_{2}^{*}, \theta_{2}\right) / \partial s_{1}}{\left(\partial \psi_{2} / \partial s_{2}\right)^{2}} \pi^{\prime \prime}\left(s_{2}^{*}\right) \leq 0 .
$$

Taking into account the intertemporal effect of the ISDS mechanism, we can, as in Appendix A.2, write the first-order condition w.r.t. $s_{1}$ as an implicit function

$$
\begin{aligned}
\psi_{1}\left(\alpha, s_{1}^{*}, \rho s_{1}\right) & =(1+\alpha)\left[\pi^{\prime}\left(s_{1}^{*}\right)+\frac{\partial \hat{\pi}_{2}}{\partial s_{1}}\right]+\theta v^{\prime}\left(s_{1}^{*}\right)+\frac{\partial \hat{R}_{2}}{\partial s_{1}}=0 \\
\text { with } \frac{\partial \psi_{1}}{\partial \alpha} & =\pi^{\prime}\left(s_{1}^{*}\right)+\frac{\partial \hat{\pi}_{2}}{\partial s_{1}}+(1+\alpha) \frac{\partial^{2} \hat{\pi}_{2}}{\partial s_{1} \partial \alpha}+\frac{\partial^{2} \hat{R}_{2}}{\partial s_{1} \partial \alpha} .
\end{aligned}
$$

Using A.9, we may write

$$
\begin{aligned}
\frac{\partial \psi_{1}}{\partial \alpha} & =\underbrace{\pi^{\prime}\left(s_{1}^{*}\right)+\int_{\bar{\theta}_{2}\left(s_{1}\right)}^{\bar{\Theta}} \pi^{\prime}\left[s_{2}^{*}(\theta)\right] \frac{\partial s_{2}^{*}(\theta)}{\partial s_{1}} \mathrm{~d} G(\theta)}_{<0} \\
& +\int_{\bar{\theta}_{2}\left(s_{1}\right)}^{\bar{\Theta}} \underbrace{\left[(1+\alpha) \pi^{\prime \prime}\left[s_{2}^{*}(\theta)\right]+\theta v^{\prime \prime}\left[s_{2}^{*}(\theta)\right]\right.}_{<0} \underbrace{\frac{\partial s_{2}^{*}(\theta)}{\partial \alpha}}_{<0} \underbrace{\frac{\partial s_{2}^{*}(\theta)}{\partial s_{1}}}_{\geq 0} \mathrm{~d} G(\theta) \\
& +\int_{\bar{\theta}_{2}\left(s_{1}\right)}^{\bar{\Theta}}\left[\pi^{\prime}\left(s_{2}^{*}(\theta)\right)-\rho t\left(s_{1}, s_{2}^{*}, \theta\right)\right] \underbrace{\frac{\partial^{2} s_{2}^{*}(\theta)}{\partial s_{1} \partial \alpha}}_{\leq 0} \mathrm{~d} G(\theta)
\end{aligned}
$$

The first line, representing the direct effect of an increase in $\alpha$ altering the weight that the regulation effects on profits receive in the government's calculation, is clearly negative. The second line represents the lowering of the marginal welfare effect, given the intertemporal effect $\partial s_{2}^{*} / \partial s_{1}$, which is positive, thus counteracting the first line. And finally, using the first-order condition (11), the final line represents the effect coming from a reduction of the magnitude of the intertemporal effect $\partial s_{2}^{*} / \partial s_{1}$. Since the bracketed term in the third line is ambiguous, this effect is ambiguous in sign.

We must thus conclude that the sign of $\partial \psi_{1} / \partial \alpha$ is ambiguous. Therefore, the sign of $\mathrm{d} s_{1}^{*} / \mathrm{d} \alpha=-\left(\partial \psi_{1} / \partial \alpha\right) /\left(\partial \psi_{1} / \partial s_{1}\right)$ is ambiguous as well. Indeed, since $\mathrm{d} s_{2}^{*} / \mathrm{d} \alpha=$ 
$\left(\partial s_{2}^{*} / \partial s_{1}\right)\left(\mathrm{d} s_{1}^{*} / \mathrm{d} \alpha\right)+\partial s_{2}^{*} / \partial \alpha$, we recognize that the intertemporal effect of a higher $s_{1}^{*}$ on $s_{2}$ may even overcompensate the direct negative effect of a higher $\alpha$ on $s_{2}^{*}$.

\section{A.4 Proof of Lemma 4}

An increase in the number of foreign firms implies:

$$
\frac{\partial s_{2}^{* *}\left(\theta_{2}, \sigma, \sigma^{*}\right)}{\partial \sigma^{*}}=-\frac{\alpha \pi^{\prime}\left[s_{2}^{* *}\left(\theta_{2}, \sigma, \sigma^{*}\right)\right]+\theta_{2} v^{\prime}\left[s_{2}^{* *}\left(\theta_{2}, \sigma, \sigma^{*}\right)\right]}{\left(\sigma(1+\alpha)+\sigma^{*} \alpha\right) \pi^{\prime \prime}\left[s_{2}^{* *}\left(\theta_{2}, \sigma, \sigma^{*}\right)\right]+\left(\sigma+\sigma^{*}\right) \theta_{2} v^{\prime \prime}\left[s_{2}^{* *}\left(\theta_{2}, \sigma, \sigma^{*}\right)\right]}>0
$$

where the numerator is positive due to the first-order condition (15), and the denominator is negative due to the second-order condition. An increase in the number of domestic firms implies:

$$
\frac{\partial s_{2}^{* *}\left(\theta_{2}, \sigma, \sigma^{*}\right)}{\partial \sigma}=-\frac{(1+\alpha) \pi^{\prime}\left[s_{2}^{* *}\left(\theta_{2}, \sigma, \sigma^{*}\right)\right]+\theta_{2} v^{\prime}\left[s_{2}^{* *}\left(\theta_{2}, \sigma, \sigma^{*}\right)\right]}{\left(\sigma(1+\alpha)+\sigma^{*} \alpha\right) \pi^{\prime \prime}\left[s_{2}^{* *}\left(\theta_{2}, \sigma, \sigma^{*}\right)\right]+\left(\sigma+\sigma^{*}\right) \theta_{2} v^{\prime \prime}\left[s_{2}^{* *}\left(\theta_{2}, \sigma, \sigma^{*}\right)\right]}<0
$$

where the numerator is negative due to the first-order condition (15). The first-order condition 15 may be written as $(1+A) \alpha \pi^{\prime}(\cdot)+\theta_{2} v^{\prime}(\cdot)=0$, where $A:=\sigma /\left(\left(\sigma+\sigma^{*}\right) \alpha\right)>$ 0 , which implies that the numerator of $(\mathrm{A} .17)$ is equal to $-A \alpha \pi^{\prime}(\cdot)>0$. By the same logic, (15) may be written as $(1-B)(1+\alpha) \pi^{\prime}(\cdot)+\theta_{2} v^{\prime}(\cdot)=0$, where $B:=\sigma^{*} /\left(\left(\sigma+\sigma^{*}\right)(1+\alpha)\right)<$ 0 , which implies that the numerator of A.18 is equal to $-B(1+\alpha) \pi^{\prime}(\cdot)>0$.

\section{A.5 Cross derivative of $s_{2}^{* *}\left(\theta_{2}, \sigma, \sigma^{*}\right)$}

For $v_{t}=\theta_{t} \ln \left(s_{t}\right)$, straightforward calculations show that the optimal second-period regulation and its derivatives are given by ${ }^{39}$

$$
\begin{array}{rlrl}
s_{2}^{* *}(\cdot) & =\frac{\theta_{2}^{2}\left(\sigma+\sigma^{*}\right)}{(1+\alpha) \sigma+\alpha \sigma^{*}}, & \frac{\partial s_{2}^{* *}(\cdot)}{\partial \sigma} & =-\frac{\theta_{2}^{2} \sigma^{*}}{\left((1+\alpha) \sigma+\alpha \sigma^{*}\right)^{2}}<0, \\
\frac{\partial s_{2}^{* *}(\cdot)}{\partial \sigma^{*}}=\frac{\theta_{2}^{2} \sigma}{\left((1+\alpha) \sigma+\alpha \sigma^{*}\right)^{2}}>0, & \frac{\partial^{2} s_{2}^{* *}(\cdot)}{\partial \sigma \partial \sigma^{*}}=\frac{\theta_{2}^{2}\left(\alpha \sigma^{*}-(1+\alpha) \sigma\right)}{\left((1+\alpha) \sigma+\alpha \sigma^{*}\right)^{3}},
\end{array}
$$

and thus $\partial^{2} s_{2}^{* *}(\cdot) / \partial \sigma \partial \sigma^{*}>(<) 0$ if $\alpha \sigma^{*}>(<)(1+\alpha) \sigma$.

\footnotetext{
${ }^{39}$ Of course, parameter restrictions apply. $\underline{\Theta} \geq\left((1+\alpha) \sigma+\alpha \sigma^{*}\right) /\left(\sigma+\sigma^{*}\right)$ guarantees that regulation benefits will be positive, and $\gamma$ must be sufficiently large.
} 


\section{A.6 Proof of Proposition 4}

The proof proceeds in two steps. First, we prove that the entry level increases with $\sigma$, if $\sigma>F\left(\bar{\phi}^{* *}\right)$ to begin with and $\partial^{2} s_{2}^{* *}(\cdot) / \partial \phi \partial \sigma<0$. Second, we prove that $\bar{\phi}^{* *}$ approaches its first best cut-off level when $\sigma \rightarrow \infty$. Let us write the first-order condition for entry as

$$
\begin{aligned}
\Psi(\cdot) & =\left[\sigma+F\left(\bar{\phi}^{* *}\right)\right] \frac{\partial \tilde{\Omega}_{2}\left(\sigma, \bar{\phi}^{* *}\right)}{\partial \phi} \\
& +f\left(\bar{\phi}^{* *}\right)\left[\left(\Omega\left(s_{1}^{* *}\right)+\tilde{\Omega}_{2}\left(\sigma, \bar{\phi}^{* *}\right)-\bar{\phi}^{* *}\right]-F\left(\bar{\phi}^{* *}\right)=0\right.
\end{aligned}
$$

where $\Omega\left(s_{1}^{* *}\right)=(1+\alpha) \pi\left(s_{1}^{* *}\right)+\theta_{1} v\left(s_{1}^{* *}\right)$. Due to the assumed concavity of the objective function, i.e., $\partial \Psi(\cdot) / \partial \phi<0$, and due to $\partial \Psi(\cdot) / \partial s_{1}=\partial^{2} \Omega / \partial s_{1} \partial \phi=0$, the change of $\bar{\phi}^{* *}$ with $\sigma$ is determined by

$$
\frac{\partial \Psi(\cdot)}{\partial \sigma}=\frac{\partial \tilde{\Omega}_{2}\left(\sigma, \bar{\phi}^{* *}\right)}{\partial \phi}+\left[\sigma+F\left(\bar{\phi}^{* *}\right)\right] \frac{\partial^{2} \tilde{\Omega}_{2}\left(\sigma, \bar{\phi}^{* *}\right)}{\partial \phi \partial \sigma}+f\left(\bar{\phi}^{* *}\right) \frac{\partial \tilde{\Omega}_{2}\left(\sigma, \bar{\phi}^{* *}\right)}{\partial \sigma}
$$

only. We now compute these partial derivatives, taking into account that $\partial s_{2}^{* *}(\cdot) / \partial \phi=$ $f(\cdot) \partial s_{2}^{* *}(\cdot) / \partial \sigma^{*}>0$ and $\partial^{2} s_{2}^{* *}(\cdot) / \partial \phi \partial \sigma=f(\cdot) \partial^{2} s_{2}^{* *}(\cdot) / \partial \sigma^{*} \partial \sigma:$

$$
\frac{\partial \tilde{\Omega}_{2}(\cdot)}{\partial \phi} f(\cdot) \int_{\underline{\Theta}}^{\bar{\Theta}}\left[(1+\alpha) \pi^{\prime}(\cdot)+\theta v^{\prime}(\cdot)\right] \frac{\partial s_{2}^{* *}(\cdot)}{\partial \phi} \mathrm{d} G(\theta)<0
$$

(because $\left.(1+\alpha) \pi^{\prime}(\cdot)+\theta v^{\prime}(\cdot)<0\right)$,

$$
\begin{aligned}
\frac{\partial \tilde{\Omega}_{2}(\cdot)}{\partial \sigma} & =\int_{\underline{\Theta}}^{\bar{\Theta}}\left[(1+\alpha) \pi^{\prime}(\cdot)+\theta v^{\prime}(\cdot)\right] \frac{\partial s_{2}^{* *}(\cdot)}{\partial \sigma} \mathrm{d} G(\theta), \\
\frac{\partial^{2} \tilde{\Omega}_{2}(\cdot)}{\partial \phi \partial \sigma} & =f(\cdot) \int_{\underline{\Theta}}^{\bar{\Theta}}\left[(1+\alpha) \pi^{\prime \prime}(\cdot)+\theta v^{\prime \prime}(\cdot)\right] \frac{\partial^{2} s_{2}^{* *}(\cdot)}{\partial \phi \partial \sigma} \mathrm{d} G(\theta) .
\end{aligned}
$$

Thus,

$$
\begin{aligned}
\frac{\partial \Psi(\cdot)}{\partial \sigma} & =f(\cdot)(\int_{\underline{\Theta}}^{\bar{\Theta}} \overbrace{\left[(1+\alpha) \pi^{\prime}(\cdot)+\theta v^{\prime}(\cdot)\right]}^{+}\left[\frac{\partial s_{2}^{* *}(\cdot)}{\partial \phi}+\frac{\partial s_{2}^{* *}(\cdot)}{\partial \sigma}\right] \mathrm{d} G(\theta) \\
& +\int_{\underline{\Theta}}^{\bar{\Theta}} \underbrace{\left[(1+\alpha) \pi^{\prime \prime}(\cdot)+\theta v^{\prime \prime}(\cdot)\right]}_{-} \frac{\partial^{2} s_{2}^{* *}(\cdot)}{\partial \phi \partial \sigma} \mathrm{d} G(\theta))
\end{aligned}
$$


If $\partial^{2} s_{2}^{* *}(\cdot) / \partial \sigma \partial \sigma^{*}<0$, the second term of A.21 is clearly positive. Now consider

$$
\frac{\partial s_{2}^{* *}(\cdot)}{\partial \phi}+\frac{\partial s_{2}^{* *}(\cdot)}{\partial \sigma}=\frac{\left(1+\frac{\alpha}{2}\right) \pi^{\prime}(\cdot)+\theta_{2} v^{\prime}(\cdot)}{\left.2\left[\left[\sigma(1+\alpha)+\sigma^{*}\right] \pi^{\prime \prime}(\cdot)\right]+\left(\sigma+\sigma^{*}\right) \theta_{2} v^{\prime \prime}(\cdot)\right)} .
$$

This term is positive if

$$
\left(1+\frac{\alpha}{2}\right) \pi^{\prime}(\cdot)+\theta_{2} v^{\prime}(\cdot)>0=\frac{\sigma(1+\alpha)+F(\cdot)}{\sigma+F(\cdot)} \pi^{\prime}(\cdot)+\theta_{2} v^{\prime}(\cdot) \Leftrightarrow \sigma>F\left(\bar{\phi}^{* *}\right)
$$

where we have used the first-order condition again. Thus, $\bar{\phi}^{* *}$ unambiguously increases with $\sigma$ (i) if $\sigma>F\left(\bar{\phi}^{* *}\right)$ and (ii) if $\partial^{2} s_{2}^{* *}(\cdot) / \partial \sigma \partial \sigma^{*}<0$. Note that these are sufficient conditions only.

So far, we have shown that the entry distortion becomes smaller with an increase in $\sigma$ if these conditions are fulfilled. However, this is not yet proof for welfare-dominance as we also have to show that the optimal cut-off level converges to the complete contract policy one with an increase in $\sigma$. If this is the case, a $\hat{\sigma}$ exists such that the national treatment provision welfare-dominates ISDS for all $\sigma \geq \hat{\sigma}$, because ISDS will always impose a distortion for $s_{1}$.

If $\sigma \rightarrow \infty$, it is obvious that $s_{2}^{* *}$ approaches the globally optimal regulation level. As for entry, the complete contract policy entry level is realized if $f\left(\bar{\phi}^{* *}\right)\left[\left(\Omega\left(s_{1}^{* *}\right)+\tilde{\Omega}_{2}\left(\sigma, \bar{\phi}^{* *}\right)-\right.\right.$ $\left.\bar{\phi}^{* *}\right]-F\left(\bar{\phi}^{* *}\right)=0$ or equivalently if $\left[\sigma+F\left(\bar{\phi}^{* *}\right)\right]\left(\partial \tilde{\Omega}_{2}\left(\sigma, \bar{\phi}^{* *}\right) / \partial \phi\right)$ converges to zero when $\sigma \rightarrow \infty$. We find this to be true, as

$$
\lim _{\sigma \rightarrow \infty}\left[\sigma+F\left(\bar{\phi}^{* *}\right)\right] \frac{\partial \tilde{\Omega}_{2}(\cdot)}{\partial \phi}=\lim _{\sigma \rightarrow \infty} \frac{\sigma+F\left(\bar{\phi}^{* *}\right)}{\frac{1}{\frac{\partial \tilde{\Omega}_{2}(\cdot)}{\partial \phi}}}=\lim _{\sigma \rightarrow \infty} \frac{\left(\frac{\partial \tilde{\Omega}_{2}(\cdot)}{\partial \phi}\right)^{2}}{\frac{\partial^{2} \tilde{\Omega}_{2}(\cdot)}{\partial \phi \partial \sigma}}=0
$$

where we have rewritten the limit in a first step such that we can use L'Hopital's Rule because both the limit of the numerator and the limit of denominator are infinite as

$$
\lim _{\sigma \rightarrow \infty} \frac{\partial \tilde{\Omega}_{2}(\cdot)}{\partial \phi}=0 \text { because } \lim _{\sigma \rightarrow \infty}(1+\alpha) \pi^{\prime}(\cdot)+\theta_{2} v^{\prime}(\cdot)=0
$$

We find that the limit is zero and the entry level approaches its complete contract policy level because

$$
\lim _{\sigma \rightarrow \infty} \frac{\partial^{2} \tilde{\Omega}_{2}(\cdot)}{\partial \phi \partial \sigma}=\lim _{\sigma \rightarrow \infty} f(\cdot) \int_{\underline{\Theta}}^{\bar{\Theta}}\left[(1+\alpha) \pi^{\prime \prime}(\cdot)+\theta_{2} v^{\prime \prime}(\cdot)\right] \frac{\partial^{2} s_{2}^{* *}(\cdot)}{\partial \phi \partial \sigma} \mathrm{d} G\left(\theta_{2}\right) \neq 0 .
$$


Again, the increase in global welfare follows from the result that the entry threshold $\bar{\phi}^{* *}$ is also too low from a global perspective and that the global welfare function is concave; see Proposition 1. As entry increases, all foreign investors, and not only the marginal investor, are better off.

\section{References}

[1] Aisbett, E., Karp, L., McAusland, C. (2010a). Compensations for indirect expropriation in international investment agreements: Implications for national treatment ad rights to invest. Journal of Globalization and Development, 1 (2), Article 6.

[2] Aisbett, E., Karp, L., McAusland, C. (2010b). Police powers, regulatory takings and the efficient compensation of domestic and foreign investors. Economic Record, 86, 367-383.

[3] Anderson, J. (1992). Domino dumping, I: Competitive exporters. American Economic Review, 82 , 65-83.

[4] Antràs, P. (2003). Firms, contracts, and trade structure. Quarterly Journal of Economics, 118, 1375-1418.

[5] Antràs, P. (2016). Global Production: Firms, Contracts, and Trade Structure, Princeton University Press.

[6] Bagwell, K., Staiger, R. (1990). A theory of managed trade. American Economic Review, 80, 779-795.

[7] Berger, A., Busse, M., Nunnenkamp, P., Roy, M. (2011). More stringent BITs, less ambiguous effects on FDI? Not a bit! Economics Letters, 112, 270-272.

[8] Bergstrand, J.H., Egger, P. (2013). What determines BITs? Journal of International Economics, 90, 107-122.

[9] Beshkar, M., Bond, E.W. (2010). Transaction costs, asymmetric countries and flexible trade agreements, mimeo.

[10] Beshkar, M., Bond, E.W., Rho, Y. (2015). Tariff binding and overhang: Theory and evidence. Journal of International Economics, 97, 1-13.

[11] Blomström, M., Koko, A. (1998). Multinational corporations and spillovers. Journal of Economic Surveys, 12, 1-31. 
[12] Blume, L., Rubinfeld, D. L. , Shapiro, P. (1984). The taking of land: When should compensation be paid? Quarterly Journal of Economics, 99, 71-92.

[13] Bond, E.W., Samuelson, L. (1986). Tax holidays as signals. American Economic Review, 76, 820-826.

[14] Bond, E.W., Samuelson, L. (1989). Bargaining with commitment, choice of techniques, and direct foreign investment. Journal of International Economics, 26, 77-97.

[15] Che, YK., Sákovics J. (2008). Hold-Up Problem. In: Palgrave Macmillan (eds), The New Palgrave Dictionary of Economics. Palgrave Macmillan, London.

[16] Doyle, C., van Wijnberge, S. (1994). Taxation of foreign multinationals: A sequential bargaining approach to tax holidays. International Tax and Public Finance, 1, 211225 .

[17] Eaton, J., Gersovitz, M. (1984). A Theory of Expropriation and Deviations from Perfect Capital Mobility. The Economic Journal, 94, 16-40.

[18] Egger, P., Merlo, V. (2012). BITs Bite: An anatomy of the impact of bilateral investment treaties on multinational firms. Scandinavian Journal of Economics, 114, 1240-1266.

[19] Görg, H. (2007). Productivity spillovers from multinational companies, in Aylward, C. and R. O'Toole (eds): Perspectives on Irish Productivity, Forfás, Dublin, 240-252.

[20] Grout, P.A. (1984). Investment and Wages in the Absence of Binding Contracts: A Nash Bargaining Approach, Econometrica. 52, 449-460.

[21] Haufler, A.,Wooton, I. (1999). Country size and tax competition for foreign direct investment. Journal of Public Economics, 71, 121-139.

[22] Haufler, A.,Wooton, I. (2010). Competition for firms in an oligopolistic industry: The impact of economic integration. Journal of International Economics, 80, 239-248.

[23] Heckemeyer, J.H., Overesch, M. (2017). Multinationals' profit response to tax differentials: Effect size and shifting channels. Canadian Journal of Economics, 50, 965-994.

[24] Horn, H., Tangerås, T. (2017). Economics and politics of international investment agreements. CEPR Discussion Paper No. 11879, Centre for Economic Policy Research, London.

[25] Horn, H., Maggi, G., Staiger, R. (2010). Trade agreements as endogenously incomplete contracts. American Economic Review, 100 , 394-419. 
[26] Janeba, E. (2019). Regulatory chill and the effect of investor state dispute settlements. Review of International Economics, forthcoming.

[27] Konrad, K.A. (2017). Large investors, regulatory taking and investor-state dispute settlement. European Economic Review, 98, 341-353.

[28] Maggi, G., Rodríguez, A. (1998). The Value of Trade Agreements in the Presence of Political Pressure. Journal of Political Economy, 106, 574- 601.

[29] Maggi, G., Staiger, R. (2018). Trade disputes and settlement. International Economic Review, 59, 19-50.

[30] Maggi, G., Staiger, R. (2015). Optimal design of trade agreements in the presence of renegotiation. American Economic Journal: Microeconomics, 7, 109-143.

[31] Maggi, G., Staiger, R. (2011). The role and design of dispute settlement procedures in international trade agreements. Quarterly Journal of Economics, 126, 475-515.

[32] MAI draft (1998), Negotiating group on the multilateral agreement on investment (MAI), The multilateral agreement on investment, draft consolidated text, OECD, 22 April 1998.

[33] Markusen, J. R. , Venables, A.J.. (1988). Trade policy with increasing returns and imperfect competition: Contradictory results from competing assumptions. Journal of International Economics, 24, 299-316.

[34] Maskin, E., Tirole, J. (1999). Unforeseen contingencies and incomplete contracts. Review of Economic Studies, 66, 83-114.

[35] Navaretti, G.B., Venables, A.J. (2006). Multinational firms in the world economy, Princeton University Press.

[36] Neumayer, E., Nunnenkamp P., Roy, M. (2016). Are stricter investment rules contagious? Host country competition for foreign direct investment through international agreements. Review of World Economics, 152, 177-213.

[37] Poulsen, L., Bonnitcha, J., Yackee. J. (2015), Transatlantic investment treaty protection, in Hamilton, D.S. and Pelkmans, J. (eds.): Rule-Makers or Rule-Takers?, Peterson Institute for International Economics, 139-186.

[38] OECD (2008), OECD Employment Outlook, Paris.

[39] OECD (2012), Investor-State Dispute Settlement, Public Consultation: 16 May - 9 July 2012, Paris. 
[40] Schjelderup, G., Stähler, F. (2019). Investor state dispute settlement and multinational firm behavior. mimeo.

[41] Stähler, F. (2019). An optimal investor state dispute settlement mechanism. mimeo.

[42] Titi, C. (2016). The European Union's proposal for an international investment court: Significance, innovations and challenges ahead. mimeo.

[43] Transnational Institute (2017). Why did Ecuador terminate all its Bilateral investment treaties? https://www.tni.org/en/article/why-did-ecuador-terminate-allits-bilateral-investment-treaties, accessed November 8, 2017.

[44] TPP (2016), Text of the Trans-Pacific Partnership, Office of the United States Trade Representative, https://ustr.gov/trade-agreements/free-trade-agreements/transpacific-partnership/tpp-full-text, accessed August 30, 2017. 